\title{
Global cloud and precipitation chemistry and wet deposition: tropospheric model simulations with ECHAM5/MESSy1
}

\author{
H. Tost, P. Jöckel, A. Kerkweg, A. Pozzer, R. Sander, and J. Lelieveld \\ Atmospheric Chemistry Department, Max Planck Institute for Chemistry, P.O. Box 3060, 55020 Mainz, Germany
}

Received: 23 November 2006 - Published in Atmos. Chem. Phys. Discuss.: 18 January 2007

Revised: 4 May 2007 - Accepted: 16 May 2007 - Published: 24 May 2007

\begin{abstract}
The representation of cloud and precipitation chemistry and subsequent wet deposition of trace constituents in global atmospheric chemistry models is associated with large uncertainties. To improve the simulated trace gas distributions we apply the new submodel SCAV, which includes detailed cloud and precipitation chemistry and present results of the atmospheric chemistry general circulation model ECHAM5/MESSy1. A good agreement with observed wet deposition fluxes for species causing acid rain is obtained. The new scheme enables prognostic calculations of the $\mathrm{pH}$ of clouds and precipitation, and these results are also in accordance with observations. We address the influence of detailed cloud and precipitation chemistry on trace constituents based on sensitivity simulations. The results confirm previous results from regional scale and box models, and we extend the analysis to the role of aqueous phase chemistry on the global scale. Some species are directly affected through multiphase removal processes, and many also indirectly through changes in oxidant concentrations, which in turn have an impact on the species lifetime. While the overall effect on tropospheric ozone is relatively small $(<10 \%)$, regional effects on $\mathrm{O}_{3}$ can reach $\approx 20 \%$, and several important compounds (e.g., $\mathrm{H}_{2} \mathrm{O}_{2}, \mathrm{HCHO}$ ) are substantially depleted by clouds and precipitation.
\end{abstract}

\section{Introduction}

Scavenging and subsequent wet deposition represent important removal processes for many trace constituents in the troposphere. They are crucial for cleansing the troposphere from aerosol particles and soluble gases and indirectly also for many less soluble species. Furthermore, multiphase chemistry can have a major impact on tropospheric compo-

Correspondence to: $\mathrm{H}$. Tost

(tost@mpch-mainz.mpg.de) sition (Ravishankara, 1997). However, the representation of wet deposition and cloud chemistry differs widely in global models, resulting in large uncertainties (Rasch et al., 2000). These uncertainties are to a large extent associated with the coarse descriptions of cloud and precipitation processes, and also with the representation of scavenging and aqueous phase chemistry (Zhang et al., 2006). Even though Levine and Schwartz (1982) and Schwartz (1986) have shown more than two decades ago that for most gases uptake according to Henry's equilibrium alone does not represent atmospheric conditions, this approximation is still commonly used in scavenging parameterisations, in particular in global models. Alternatively, fixed scavenging coefficients are applied, implicitly assuming that the process only varies as a function of the precipitation flux. The treatment of chemical reactions of dissolved gases in clouds and precipitation has largely focused on sulphur species (e.g. Berglen et al., 2004).

A model intercomparison of cloud chemical parcel models focusing mainly on the oxidation of $\mathrm{SO}_{2}$ in the aqueous phase (including the basic aqueous phase transfer and chemical reactions) has shown that large uncertainties arise from different parameterisations (Kreidenweis et al., 2003). More detailed cloud chemistry schemes have been applied in smaller scale models (box models, cloud parcel models, single column models), e.g. by Chameides and Davis (1982); Jacob (1986); Lelieveld and Crutzen (1991); Bott and Carmichael (1993); Monod and Carlier (1999); Fahey and Pandis (2001); von Glasow et al. (2002); Ervens et al. (2003); Leriche et al. (2003); Barth et al. (2003) and references therein; Kreidenweis et al. (2003) and references therein, and detailed information about the processes involved has been gained. However, from these results it is difficult to estimate the large-scale effects of multiphase chemistry. Lelieveld and Crutzen (1991) have derived the global tropospheric impact by applying their chemical box-model in combination with a global cloud data set. The application of the model of Liang and Jacob (1997) in the regional model of Jacob et al.

Published by Copernicus Publications on behalf of the European Geosciences Union. 
(1993) leads to the conclusion of a minor impact of multiphase chemistry on the regional scale, although this was only valid for the simulated period and domain addressed, and the extrapolation to the global scale is not straightforward.

Fahey and Pandis (2003) have increased the amount of detail and the model complexity, and calculated droplet size resolved cloud chemistry in a 3D regional transport model. Yet, this model setup is quite complex and therefore it has not been applied in an atmospheric chemistry general circulation model (AC-GCM). Global models including cloud and precipitation chemistry often lack comprehensiveness to simulate the interconnected effects in the gas and liquid phase. For example, Stier et al. (2005) calculated in-cloud $\mathrm{SO}_{2}$ oxidation, but used prescribed distributions for the oxidants. Since some of these models aim at the investigation of the global sulphur cycle (e.g. Feichter et al., 1996; Rostayn and Lohmann, 2002; Dentener et al., 2006; Berglen et al., 2004), this might be appropriate, though it also introduces large uncertainties. Crutzen and Lawrence (2000) determined the effects of trace gas scavenging in a 3D global model, however, did not assess multiphase chemistry in clouds and precipitation. Global model studies explicitly considering aqueous phase chemistry may exist (e.g. Dentener, 1993), though not reported in the peer reviewed literature. Dentener and Crutzen $(1993,1994)$ applied several heterogeneous reactions including $\mathrm{NH}_{3}$ chemistry and their influence on gas phase composition. Roelofs and Lelieveld (1995) introduced additional aqueous phase reactions including e.g., $\mathrm{HCHO}$ and $\mathrm{HCOOH}$ in their model to assess multiphase chemistry, although non-methane-hydrocarbon (NMHC) chemistry was neglected and both the gas and aqueous phase reaction mechanisms applied are not easily expandable.

In the present study the scavenging and subsequent wet deposition of trace species in the ECHAM5/MESSy1 model is presented, and the influence of more detailed cloud and precipitation chemistry on the tropospheric composition is investigated with the recent submodel SCAV (Tost et al., 2006a). Following a short model description in Sect. 2, the simulation setup is outlined in Sect. 3. The results, presented in Sect. 4, distinguish three aspects: the evaluation of the wet deposition fluxes (4.1), the analysis of global $\mathrm{pH}$ values in clouds and precipitation (4.2) and the influence of liquid phase chemistry on the gas phase composition of the troposphere (4.3). The scavenging of aerosol species is not explicitly evaluated in this study. However, the relevant processes are implemented in the SCAV submodel and can be used in studies of both soluble and less soluble aerosol particles, how these are incorporated into the droplets and to what extent they take part in liquid phase chemical reactions. These latter issues will be addressed in future publications. However, the contribution of scavenged particulate sulphate and nitrate to the amount of dissolved sulphur(VI) and nitrate is also considered in this study.

In addition to cloud chemistry effects that have been investigated in the past, the effects of the chemical processes in the liquid precipitation are directly addressed, i.e., not only the vertical downward transport within hydrometeors, but also the precipitation chemistry during the falling phase are taken into account.

\section{Model description}

In this study the atmospheric chemistry general circulation model ECHAM5/MESSy1 has been applied combining the 5th generation European Centre - Hamburg model (Roeckner et al., 2006; Hagemann et al., 2006; Wild and Roeckner, 2006) (version 5.3.01) and the Modular Earth Submodel System (Jöckel et al., 2005) (version 1.1). The global meteorology is calculated by ECHAM5 based on a spectral representation of the prognostic variables vorticity, divergence, temperature, and the logarithm of the surface pressure, as well as grid point representations of specific humidity, cloud water, and cloud ice. In the vertical, a hybrid pressure coordinate system is applied. The processes of radiation and cloud microphysics are parameterised, as described in the ECHAM5 documentation (Roeckner et al., 2003, 2004). Advection of the prognostic tracers is calculated with the Lin and Rood (1996) flux-form semi-lagrangian transport algorithm. A first application of ECHAM5/MESSy1 as AC-GCM including a more detailed model description is presented in Jöckel et al. (2006). Since the wet deposition from the evaluation simulation from Jöckel et al. (2006) is used, the model configuration will be shortly summarised in the next section.

MESSy contains submodels for atmospheric chemistry, transport, their feedbacks on the meteorology through radiative transfer, and diagnostic tools. For the present study we applied the MESSy submodels RAD4ALL (for radiation calculations), CONVECT (convection parameterisation (Tost et al., 2006b)), CLOUD (large scale condensation), CVTRANS (convective tracer transport (Tost, 2006)) and ONLEM, OFFLEM, TNUDGE (emissions and pseudoemissions, described in detail by Kerkweg et al. (2006b)), LNOX $\left(\mathrm{NO}_{\mathrm{x}}\right.$ emissions from lightning), TROPOP (diagnostics of tropopause and boundary layer height), PTRAC (passive tracers), MECCA (gas phase chemistry (Sander et al., 2005)), JVAL (photolysis rates for chemistry calculations), HETCHEM (reaction rates for heterogeneous chemical reactions on aerosols), M7 (aerosol microphysics (Vignati et al., 2004; Kerkweg, 2005)), DRYDEP (dry deposition of trace gases and aerosol particles (Ganzeveld et al., 1998; Kerkweg et al., 2006a)), SEDI (sedimentation of aerosol particles (Kerkweg et al., 2006a)), and SCAV (scavenging and liquid phase chemistry in clouds and precipitation (Tost et al., 2006a)). A more detailed description of the submodels can also be found on the MESSy web page ${ }^{1}$. Since wet deposition and cloud and precipitation chemistry are calculated by SCAV, this submodel is the major focus of this study and its

\footnotetext{
${ }^{1}$ http://www.messy-interface.org
} 
functionality is shortly described. For more details and the parameterisations used for the individual processes we refer to Tost et al. (2006a).

SCAV calculates the uptake of aerosol particles and trace gases into cloud and precipitation droplets. Since the global model does not provide detailed information on droplet spectra, all calculations are based on bulk quantities, even though for the gas transfer velocities and scavenging efficiencies droplet size spectra according to Best (1950) are assumed, since the transfer coefficient of the mean radius is not identical to the mean transfer coefficient. The aqueous phase chemistry, including the transfer of gaseous compounds, dissociation of acidic and alkaline species in the droplets and aqueous phase redox reactions are calculated by a coupled system of ordinary differential equations using the kinetic pre-processor (KPP) software (Damian et al., 2002). The chemical reaction system for both gas and aqueous phase (MECCA and SCAV) and the applied Henry's law and accommodation coefficients are given in the supplementary material of this paper (http://www.atmos-chem-phys.net/7/ 2733/2007/acp-7-2733-2007-supplement.pdf). The gas and the liquid phase chemical processes are fully coupled and do not require prescribed mixing ratios or $\mathrm{pH}$ values. For the scavenging of aerosol compounds we refer to the detailed submodel description by Tost et al. (2006a), noting that size dependent scavenging efficiencies for cloud and rain droplets are included.

\section{Simulation setup}

The results used in this study refer to the ECHAM5/MESSy1 evaluation simulation (EVAL S1), obtained with the lower and middle atmosphere model configuration described in Jöckel et al. (2006), using a spectral resolution of T42 (with a resolution of approximately $2.8^{\circ} \times 2.8^{\circ}$ of the corresponding quadratic Gaussian grid) and 90 vertical levels up to $0.01 \mathrm{hPa}$ ( $\approx 80 \mathrm{~km}$, as the mid of the uppermost layer) altitude, covering a simulation period from 1998 to 2005 . We additionally performed a series of shorter simulations for the year 2000 with a tropospheric configuration of the model, which has a reduced vertical resolution especially in the upper troposphere and tropopause region (31 levels up to the mid of the uppermost model layer at $10 \mathrm{hPa}$ ). Furthermore, the sensitivity calculations include the following modifications in the setup of the SCAV submodel:

- SCM (scavenging minimum): The same small set of chemical reactions in the aqueous phase is applied as in Jöckel et al. (2006) (labelled Scm in the reaction table of the electronic supplement http://www.atmos-chem-phys.net/7/2733/2007/

acp-7-2733-2007-supplement.pdf). It deals with the uptake of the most soluble compounds, the associated acid-base equilibria and the $\mathrm{SO}_{2}$ oxidation in the liquid phase by $\mathrm{O}_{3}$ and $\mathrm{H}_{2} \mathrm{O}_{2}$.
- COM (complex aqueous phase chemistry): A relatively detailed chemical reaction set is applied in a more comprehensive simulation, including more than 150 reactions in the liquid phase (labelled Sc in the reaction table of the supplement).

- EASY: A highly simplified approach is applied, with the gas-liquid partitioning only according to physical Henry's law coefficients. No aqueous phase chemistry is included.

- EASY2: A simplified approach is applied, with the gasliquid partitioning according to effective Henry's law coefficients (e.g. Sander, 1999), assuming a pH value of 5 in clouds and precipitation. No aqueous phase chemistry is included.

- NOSCAV (no scavenging): For comparison, an additional simulation has been performed in which aqueous phase chemistry, scavenging, and wet deposition are neglected.

Furthermore, as mentioned in Jöckel et al. (2006), a different precipitation liquid water content (LWC) has been applied, now using the amount of water from the precipitation flux and not longer a parameterised LWC (Mason, 1971). This results in a more realistic scavenging representation in the four sensitivity simulations. The simulation period for the sensitivity experiments spans one year each, plus three months of spin-up, initialised with chemical data from the evaluation simulation (S1) of Jöckel et al. (2006). To approximate realistic, i.e. analysed meteorological conditions, the surface pressure is adjusted towards the surface pressure from European Centre for Medium-range Weather Forecasting (ECMWF) analyses for the year 2000 using a nudging technique (Jeuken et al., 1996; van Aalst et al., 2004). The coupling between chemistry and dynamics through radiation feedbacks has been switched off to simulate comparable meteorology in the sensitivity studies. Nevertheless, the dynamics of the various simulations are not fully identical due to interactions of water vapour in stratospheric chemistry interactions. A small change in one species, e.g. $\mathrm{O}_{3}$ in the troposphere can propagate into the stratosphere and influence the $\mathrm{H}_{2} \mathrm{O}$ production from methane oxidation due to the non-linearity of the chemistry. This consequently can have a small impact on the hydrological cycle (radiation, cloud water and ice). However, due to the nudging the meteorological patterns are mostly similar.

\section{Results}

The precipitation distribution and the hydrological cycle of the ECHAM5/MESSy1 model have been discussed in Jöckel et al. (2006). Furthermore, the influence of the convection parameterisation on the hydrological cycle is analysed in Tost et al. (2006b), especially to illustrate the uncertainties 


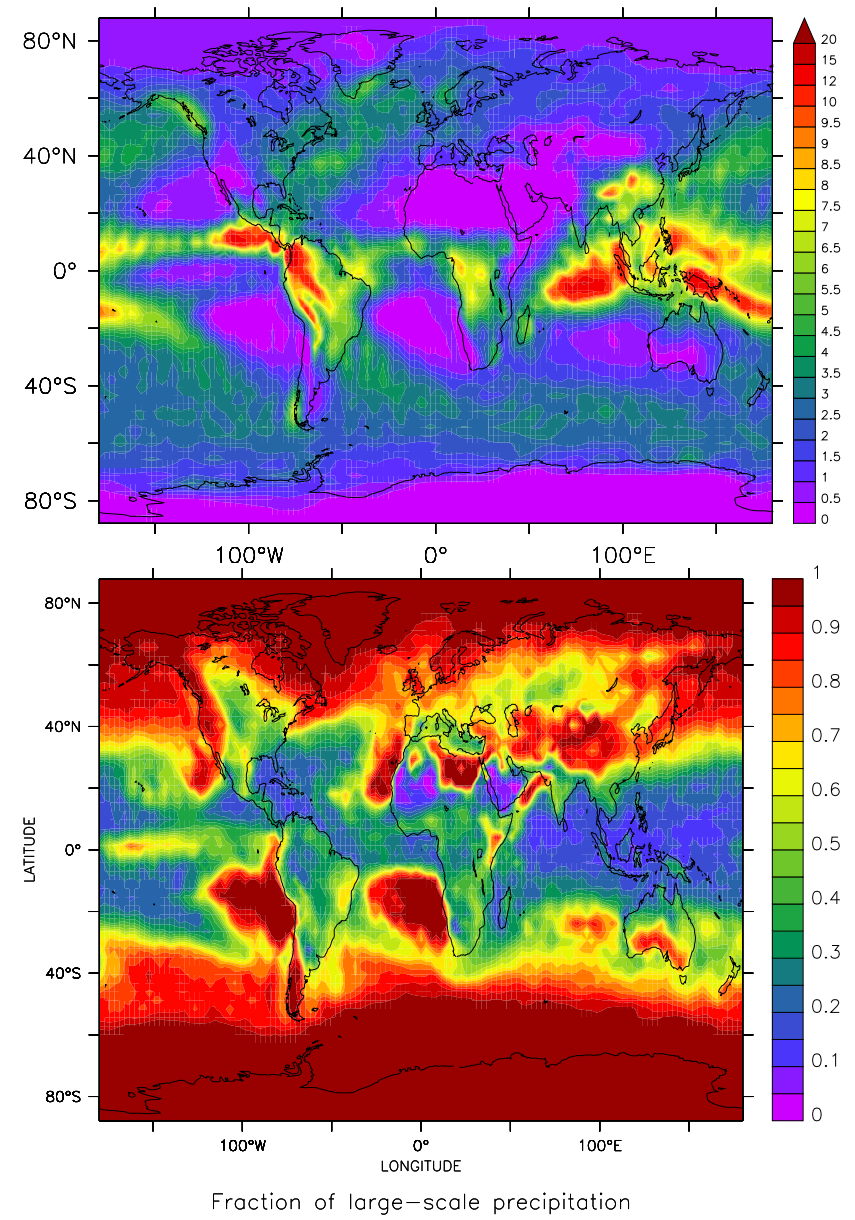

Fig. 1. Annual average precipitation rate in $\mathrm{mm} /$ day of the EVAL S1 (Jöckel et al., 2006) simulation (upper panel) and fraction of the large-scale to the total precipitation (lower panel).

associated with convective precipitation simulations. Since the locations and rates of precipitation are essential for the wet deposition of trace species, the average rainfall is presented in the upper panel of Fig. 1.

The strongest precipitation occurs in the tropics, with the maximum over the Pacific warm pool region, the Indian Ocean, and the South Pacific Convergence Zone (SPCZ). A second maximum appears west of Central America. Both maxima mainly result from convective activity. The midlatitude storm tracks are characterised by bands of moderate precipitation originating from both large-scale and convective cloud formation. Relative to observations the simulated precipitation is overestimated in the tropics, but compares well with the rainfall distribution in the mid-latitude storm tracks (slight underestimation over the northern hemispheric continents) (Tost et al., 2006b). A comparison of the simulated precipitation with data from the Global Precipitation Climatology project $\left(\mathrm{GPCP}^{2}\right)$ results in a high bias by the

\footnotetext{
${ }^{2}$ http://precip.gsfc.nasa.gov/
}

model of $0.36 \mathrm{~mm} /$ day with a mean value of $2.97 \mathrm{~mm} /$ day for the model and $2.61 \mathrm{~mm} /$ day for the GPCP data for the year 2000. The correlation between model and observations is $R^{2}=0.69$ and the linear regression results in an intercept of $0.572 \mathrm{~mm} /$ day and a slope of 0.6538 .

A similar conclusion about the representation of the precipitation distribution can be drawn from the comparison with TRMM satellite data and the CMAP precipitation dataset (compare Tost et al. (2006b)). The lower panel of Fig. 1 shows that the large-scale fraction of the total precipitation is less than $20 \%$ in the tropics, with increasing values towards the poles. At mid-latitudes, the large-scale fraction is on average more than $70 \%$. In the subtropical regions precipitation rates are typically low, which is realistically simulated by the model, because convection is suppressed by large-scale subsidence. Overall, the precipitation distribution is reproduced relatively well by the model with some limitations (Hagemann et al., 2006; Tost et al., 2006b), i.e. local underestimations at the mid-latitudes but overestimations over the tropical oceans. These limitations will have to be considered in the evaluation of wet deposition patterns by comparisons with measurement data.

\subsection{Evaluation of wet deposition fluxes}

\subsubsection{Wet deposition fluxes in the EVAL S1 simulation}

In this subsection the model calculated wet deposition fluxes from the reference simulation, as presented by Jöckel et al. (2006), for nitrate $\left(\mathrm{HNO}_{3, \text { aq }}\right.$ and $\left.\mathrm{NO}_{3}^{-}\right)$, sulphate $\left(\mathrm{HSO}_{4}^{-}\right.$and $\left.\mathrm{SO}_{4}^{2-}\right)$ and $\mathrm{NH}_{\mathrm{x}}\left(\mathrm{NH}_{3, \text { aq }}\right.$ and $\left.\mathrm{NH}_{4}^{+}\right)$are compared with measurements.

\section{Observational data}

The observational data used are from several measurement networks. The data set has been composed by Dentener et al. $(2006)^{3}$ (further denoted as D06).

For North America observations from the North American Deposition Program (NADP) ${ }^{4}$, and for Europe from the EMEP network ${ }^{5}$ for the year 2000 are used. Additionally, IGAC DEBITS Africa ${ }^{6}$ (IDAF) measurements are used for the African continent. The data include annual averages from 1996 to 1999. Measurements for East Asia are taken from the Acid Deposition Monitoring Network in East Asia (EANET) for the year 2000 and some stations from the Integrated

\footnotetext{
${ }^{3}$ Note, that the stations taken into account are not completely identical to D06. Therefore, small differences for the observation average values are found in Table 3 .

${ }^{4}$ data available through the internet from: http://www.nadp.sws. uiuc.edu, compare Hicks (2005)

${ }^{5}$ http://www.nilu.no/projects/ccc/emepdata.html

${ }^{6}$ http://www.medias.obs-mip.fr/idaf (e.g. Galy-Lacaux and Modi, 1998; Sigha-Nkamdjou et al., 2003; Yoboué et al., 2005; Mphepya et al., 2006, 2004)
} 
Table 1. Number of wet deposition observations from the individual networks.

\begin{tabular}{lccc}
\hline & Nitrate & Sulphate & $\mathrm{NH}_{\mathrm{x}}$ \\
\hline all stations & 371 & 366 & 359 \\
NADP & 227 & 228 & 227 \\
EMEP & 41 & 41 & 39 \\
EANET & 23 & 13 & 23 \\
IDAF & 8 & 8 & 8 \\
India & 44 & 48 & 34 \\
S. America & 16 & 16 & 16 \\
\hline
\end{tabular}

Monitoring Program on Acidification of Terrestrial Ecosystems (IMPACT) in China from 2001 to 2003 . For India we use observations by Kulshrestha et al. (2005), whereby some stations have been selected as mentioned in D06, with data from the period 1995-2000. South American data have originally been collected by Dentener and Crutzen (1994), Filoso et al. (1999), and Lara et al. (2001). Additionally, the D06 dataset includes observations described by Galloway et al. ${ }^{7}$ for the period 1980 - 1999 from a number of remote stations (several islands, Australia, South America). Some measurement stations have been excluded if a time series of at least one year was not available. The number of observations from the networks is listed in Table 1.

The comparison with observations is usually difficult, since the large spatial and temporal heterogeneity of precipitation and its chemical composition cannot be simulated in detail with a global model using a grid width of a few hundred kilometres. Nevertheless, the comparison can give indications to what extent the overall patterns are captured accurately by the model.

\section{Nitrate}

The nitrate wet deposition distribution is shown in Fig. 2. The upper panel shows the average annually accumulated nitrate content in precipitation from the EVAL S1 simulation in $\mathrm{mg} \mathrm{N} / \mathrm{m}^{2}$ (containing both scavenged aerosol nitrate and dissolved gaseous $\mathrm{HNO}_{3}$ and $\mathrm{N}_{2} \mathrm{O}_{5}$ ). Two major local wet deposition maxima are evident: in China, resulting mainly from the strong emissions of nitric oxides $\left(\mathrm{NO}_{\mathrm{x}}\right)$ mostly from fossil energy use, and in Central Africa, where the anthropogenic emissions are dominated by residential biofuel use and biomass burning. Furthermore, large deposition rates are also calculated for the eastern USA and western Europe, both mainly from fossil fuel related $\mathrm{NO}_{\mathrm{x}}$ emission sources. In southeast Asia, Amazonia and Central Africa additionally the natural $\mathrm{NO}_{\mathrm{x}}$ emissions from soils significantly contribute to the nitrate content of precipitation. $\mathrm{NO}_{\mathrm{x}}$ production from lightning plays a minor role for wet deposition (globally $\approx 5 \%$ of the total emissions are from lightning, mainly over

\footnotetext{
${ }^{7}$ manuscript in preparation
}
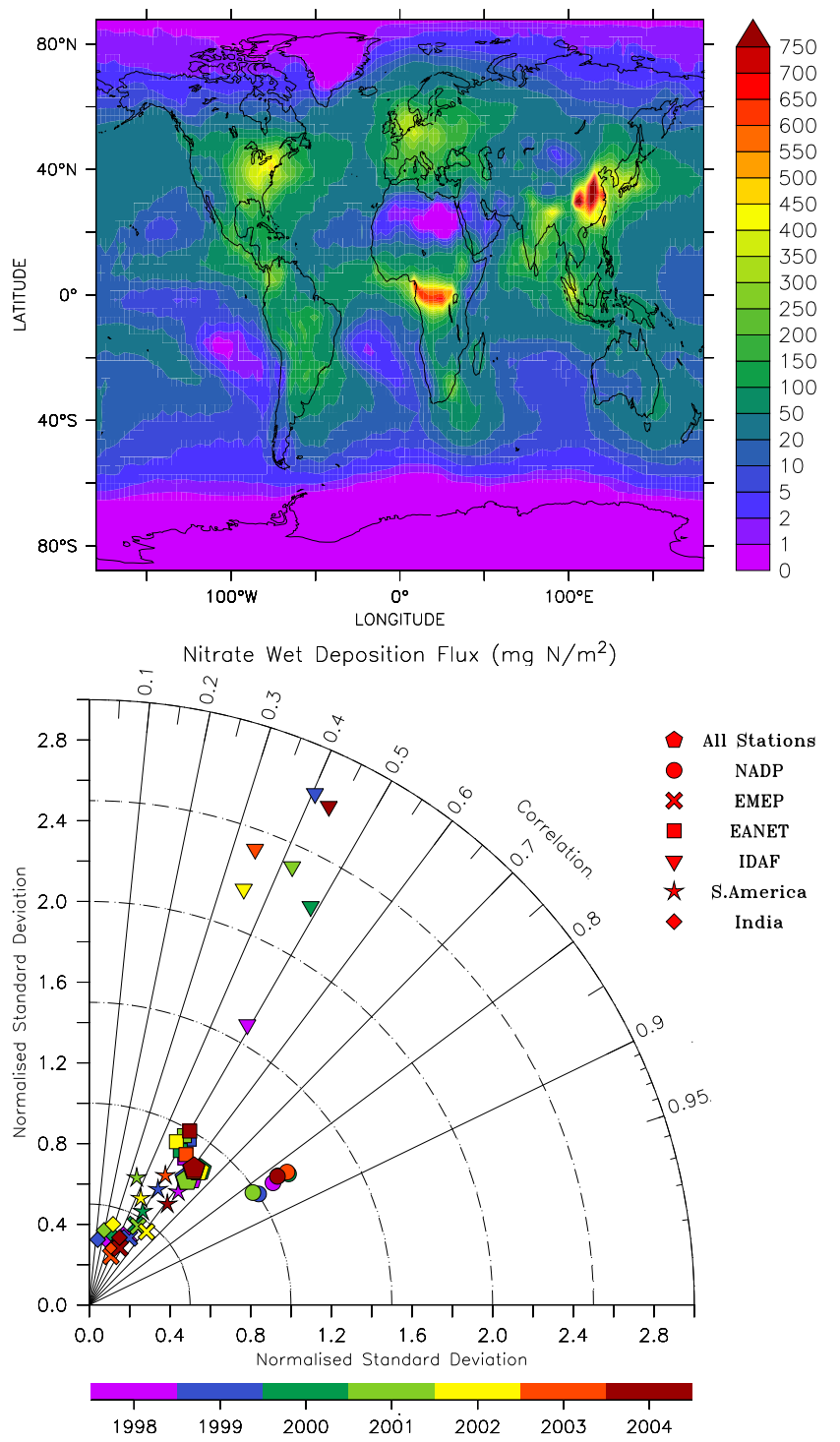

Fig. 2. Average annually accumulated wet deposition of nitrate in $\mathrm{mg} \mathrm{N} / \mathrm{m}^{2}$ (upper panel) and comparison with observations in a Taylor diagram (lower panel) showing the correlation and the standard deviation of the model normalised to the standard deviation of the observations. The individual years of the simulation (colour coded) are each compared with the measurement data set. The symbols denote the different measurement networks and the composite of all observations (pentagons).

the land masses in the tropics). Over the tropical continents the large amounts of precipitation lead to an almost complete scavenging of nitric acid $\left(\mathrm{HNO}_{3}\right)$ from the gas phase, while in the northern hemispheric storm tracks highly efficient wet deposition of $\mathrm{HNO}_{3}$ is most evident over the Atlantic Ocean. The latter is also a consequence of the incomplete scavenging close to the North American east coast (due to the lower and more episodic characteristics of the precipitation compared to the tropics) and subsequent westward transport before the atmospheric pollution is removed from the atmosphere. 


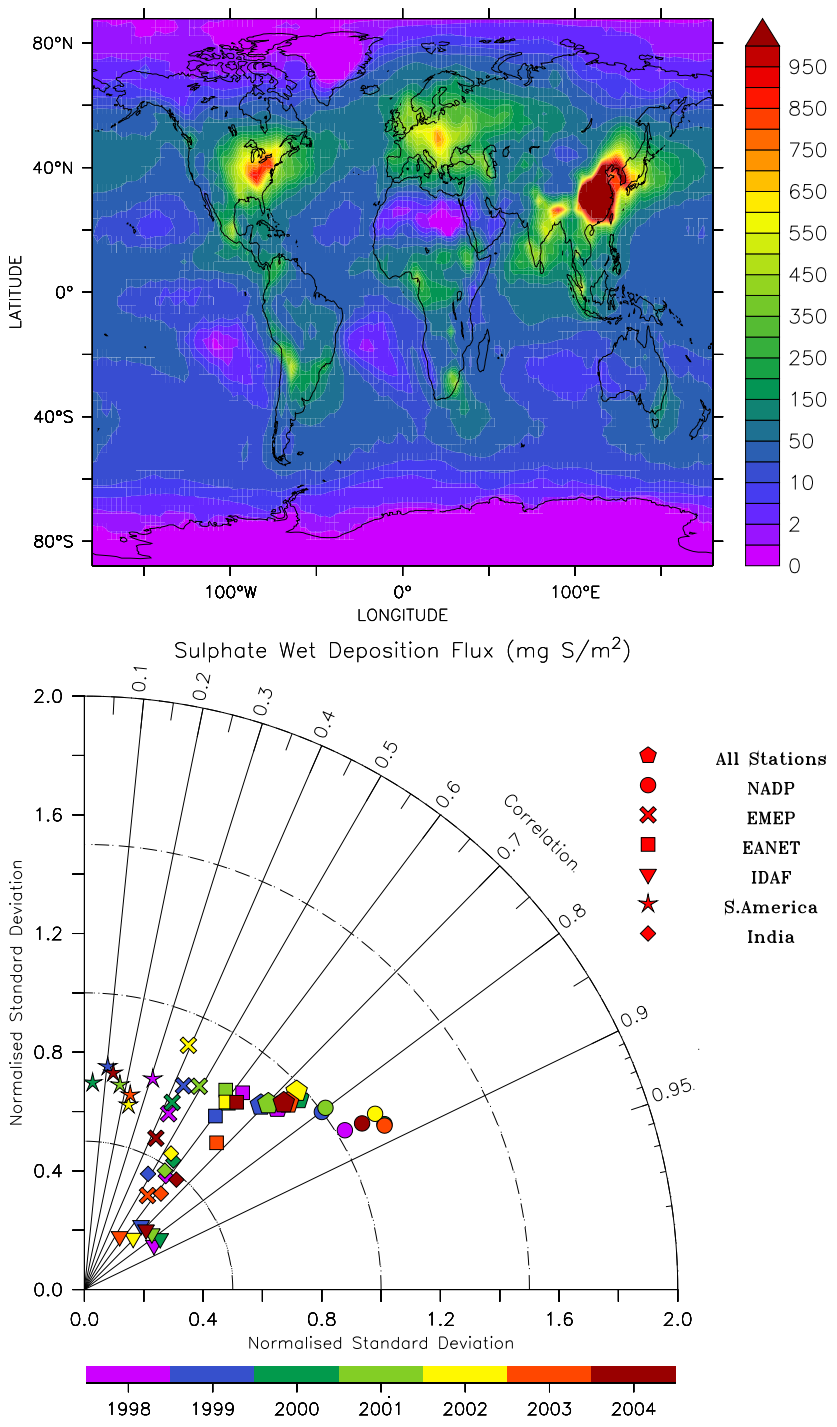

Fig. 3. Average annually accumulated wet deposition of sulphate in $\mathrm{mg} \mathrm{S} / \mathrm{m}^{2}$ (upper panel) and comparison with observations in a Taylor diagram (lower panel). For the notation see Fig. 2.

The lower panel of Fig. 2 depicts the comparison of nitrate wet deposition of the individual years to the observations described above, both for all stations (pentagons) and differentiated for the individual regions (other symbols) in a Taylor diagram (Taylor, 2001). The diagram relates the correlation between model results and measurements with the standard deviation of the model results, normalised to the standard deviation of the measurements. Since the observational data do not provide global coverage point-to-point comparisons between the station locations and the closest coordinates within the model grid are performed. The overall correlation for all years is $R \approx 0.6$ with a normalised standard deviation $\sigma^{\star} \approx 0.8$ $\left(\sigma^{\star}=\sigma_{\mathrm{mod}} / \sigma_{\mathrm{obs}}\right)$, indicating an underestimation of the amplitude of the spatial variation. For the most comprehensive NADP data set only, the model shows a higher correspon- dence with a correlation of $R>0.8$ for all years and a normalised $\sigma$ between 1 and 1.2. For the data from the other networks the correlation is much lower (around 0.4 to 0.5 ). Furthermore, the amplitude of the variability is hardly matched accurately: $\sigma^{\star}$ ranges from around 2.5 for the African measurements (indicating a strong overestimation of the variation of model wet deposition in this area) to 0.3 for some data from the EMEP and Indian observations (indicating underestimation of the spatial variation of the wet removal of nitric acid and nitrate in these regions). This can be related to the scavenging process, but as well to an inadequate representation of other processes, mainly emissions, but also chemistry, transport, and precipitation distributions. As an example, the African measurements are mostly substantially lower than the simulated values. This most likely results from the overestimated biomass burning emissions in the model, leading to too high $\mathrm{NO}_{\mathrm{x}}$ emissions and subsequent wet deposition over the African continent. Moreover, the model formulation for convective scavenging also contributes to this overestimation: instead of the total convective cloud water only the precipitating fraction is used for the nucleation scavenging. In a short sensitivity simulation using the total convective cloud water this overestimation over Central Africa was slightly reduced. And finally, it should be noted that the total precipitation over Central Africa is overestimated by the model compared to GPCP rainfall data. Nevertheless, since the agreement for sulphate and $\mathrm{NH}_{\mathrm{x}}$ is better for this region, we conclude that the high emissions of $\mathrm{NO}_{\mathrm{x}}$ are likely responsible for the differences between model and observations.

For the IDAF data the interannual variability of the model is high, whereas it is minor for the other measurement networks. The deviation from the observations cannot only be attributed to the emissions for a specific year, since the set of sensitivity simulations for the year 2000, which is included in most of the measurement data, shows a similar behaviour. We can also not exclude that some of the measurement data are not representative of the surrounding area of the size of the model grid due to the large heterogeneity of the terrain and consequently rainfall and wet deposition patterns and the sparse observatory locations. Yet, as it is the only available dataset for this region it can be applied, if its uncertainties originating partly from the low spatial observation density are taken into account.

\section{Sulphate}

The wet deposition of sulphate occurs mainly in the vicinity of the emission sources of sulphur dioxide $\left(\mathrm{SO}_{2}\right)$, of which a small fraction is oxidised in the gas phase, whereas the more important oxidation pathway is in the aqueous phase (e.g. Warneck, 1999). The average annually accumulated deposition flux is shown in the upper panel of Fig. 3. The largest wet deposition fluxes are calculated for China, where the $\mathrm{SO}_{2}$ emissions are strongest. Additional local maxima are computed for the industrialised regions in the eastern USA and 
Central Europe. In many of these regions energy production relies on coal types with a high sulphur content, resulting in substantial $\mathrm{SO}_{2}$ emissions and consequent sulphate deposition.

The comparison with the observations depicted in the lower panel of Fig. 3 shows a relatively high correlation between the model results and the measurements if we include all stations, $R \approx 0.7$, with the normalised standard deviation close to 1 . As for nitrate, the NADP data is even higher correlated, and the normalised $\sigma$ is slightly above 1 . For most other networks the correlation is lower, but except for South America, always higher than 0.3 . The amplitude of the variation is captured relatively well, with $\sigma^{\star}$ values typically between 0.6 and 1.3. For the 16 stations in South America the representation of the observed values by the model is relatively poor.

\section{Ammonia - Ammonium}

The wet deposition fluxes of $\mathrm{NH}_{\mathrm{x}}$ compounds, shown in the upper panel of Fig. 4, are also highest in regions where the emissions are typically strongest, i.e., in China and India, and slightly lower in western Europe, eastern USA, Central Africa and the northern part of South America. While in East Asia, North America and Europe both agricultural and industrial emissions are the main sources, in Africa and South America biofuel use and biomass burning dominate the atmospheric ammonia burden. In contrast to nitrate and sulphate higher wet deposition occurs in the tropical ITCZ, both over land and the ocean. This partly results from a neglect of the chemical loss of $\mathrm{NH}_{3}$ in the gas phase (oxidation by $\mathrm{OH}$ ). Furthermore, the effects of uncertainties of the simulated precipitation rates become increasingly important for moderately soluble species such as $\mathrm{NH}_{3}$. However, since observations are very scarce over the tropical oceans, it is difficult to judge if these features are real or an artefact of the model.

The correspondence of the model results with the observations is shown in the lower panel of Fig. 4. The overall correlation by including all stations is $R \approx 0.6$, and the comparison indicates a slight underestimate of the spatial variation $\left(\sigma^{\star} \approx 0.6\right)$. Again, for the dense measurement network of the USA the agreement is best. While the correlation for Europe and South America are both higher than 0.7, $\sigma^{\star}$ is either too low (for Europe) or too high (for South America). The correspondence for the African and especially the Indian stations is less good ( $R$ between 0.3 and 0.5 ).

\section{Summary}

It is obvious that the model representation of these three compounds of rainwater are of different quality for the different regions. For example, for South America $\mathrm{NH}_{\mathrm{x}}$ wet deposition is simulated quite accurately, but the simulated sulphate wet deposition is hardly correlated with the observa-
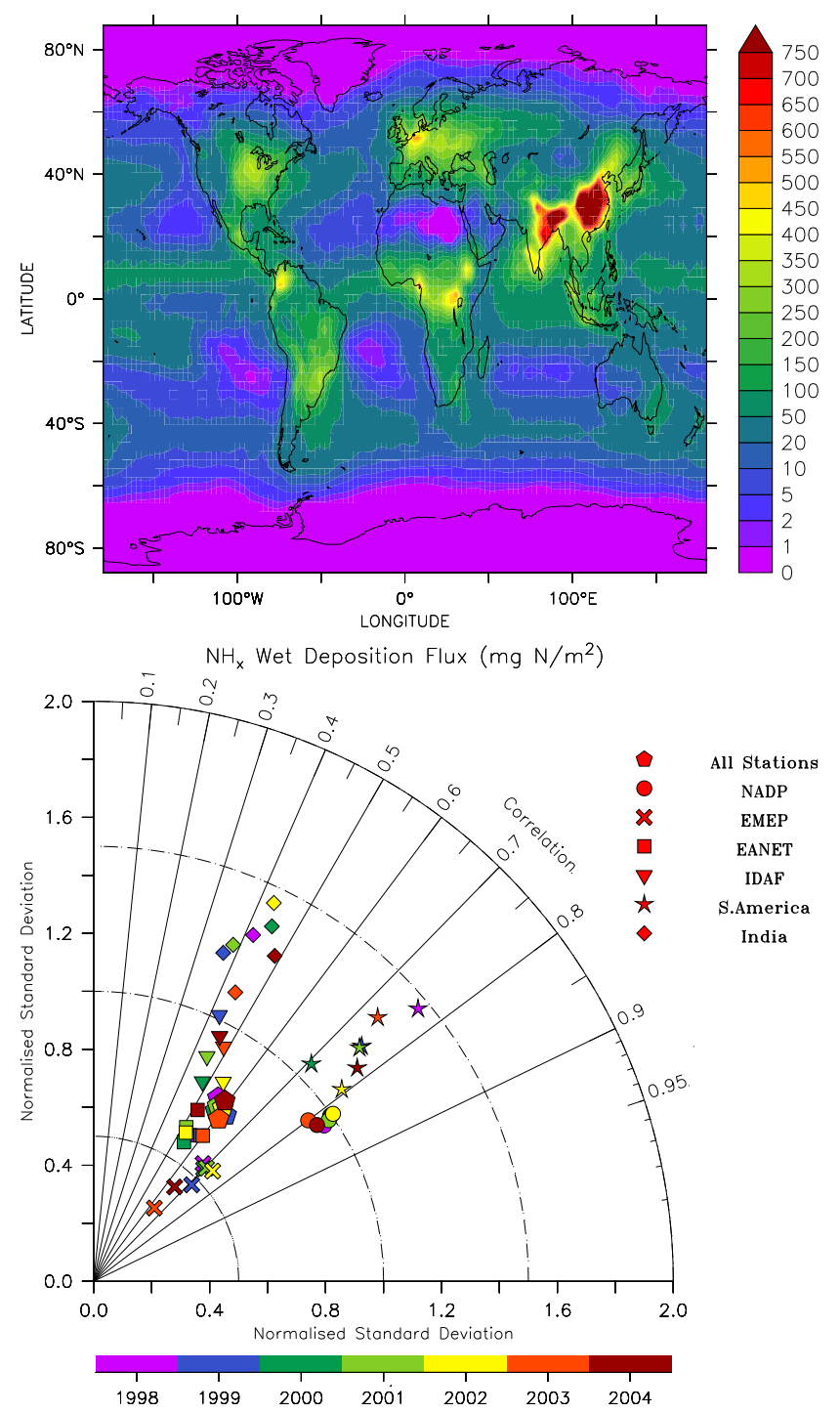

Fig. 4. Average annually accumulated wet deposition of ammonia and ammonium in $\mathrm{mg} \mathrm{N} / \mathrm{m}^{2}$ (upper panel) and comparison with observations in a Taylor diagram (lower panel). For the notation see Fig. 2.

tions. This might be related to a high sulphate burden over Chile, resulting from high values in the $\mathrm{SO}_{2}$ emission dataset for this region. It must be emphasised, that not only the observations are best with respect to the operational quality and the amount of data points in time and space for NADP, but also the available emission datasets from North America and Europe are of much higher quality compared to African and South American data because of the denser observation networks.

In comparison with other modelling studies the correspondence between the observations and model results is similar. In the model intercomparison of wet deposition of nitrate, sulphate and ammonia by D06 similar correlations are achieved as shown in Table 2. However, some differences to 
Table 2. Correlation for nitrate, sulphate and $\mathrm{NH}_{\mathrm{X}}$ from this study and D06.

\begin{tabular}{ccccccc}
\hline & \multicolumn{2}{c}{ nitrate } & \multicolumn{2}{c}{ sulphate } & \multicolumn{2}{c}{$\mathrm{NH}_{\mathrm{x}}$} \\
this & & \multicolumn{3}{c}{$\begin{array}{c}\text { this } \\
\text { this }\end{array}$} & & \\
& study & D06 & study & D06 & study & D06 \\
\hline NADP & 0.84 & 0.84 & 0.86 & 0.88 & 0.83 & 0.80 \\
EMEP & 0.54 & 0.44 & 0.46 & 0.44 & 0.70 & 0.73 \\
EANET & 0.51 & 0.56 & 0.62 & 0.63 & 0.55 & 0.47 \\
IDAF & 0.42 & 0.74 & 0.74 & 0.93 & 0.49 & 0.90 \\
\hline
\end{tabular}

the study of D06 result not only from the different process formulation in our model, but also from different emission inventories.

Only for the African data the representation by our model seems substantially poorer. However, these results originate from very few data points and the comparison should be weighted less as for instance with the comprehensive NADP dataset for which we obtain very good agreement. A comparison for the absolute values of the observed and simulated wet deposition fluxes is given in Table 3 .

Even though the simulated precipitation is generally too strong in the tropics, this hardly affects the comparison with the observations, since the regions with the most pronounced overestimation are located over the ocean, where no wet deposition data is available. Nevertheless, the unrealistically strong rainfall in the Himalaya region (cf. Tost et al., 2006b) leads to enhanced wet deposition in this region. Additionally, the enhanced wet deposition in Central Africa and eastern China can also be partially related to overestimations in the convective precipitation.

Different model agreement for nitrate, sulphate and $\mathrm{NH}_{\mathrm{x}}$ as well as the differences in the interannual variability indicate that this is likely not only caused by the wet deposition formulation, but also by emissions, transport and chemical processes.

4.1.2 Sensitivity on the details of the scavenging/liquid phase chemistry process description

In this section the sensitivity studies with the 31 layer tropospheric model configuration are compared for the year 2000. Since in NOSCAV wet deposition is not calculated at all this simulation is ignored in this section. Additionally, in the four simulation setups the above mentioned change of the precipitation liquid water content has been applied. Since the chemical setup of the SCM simulation is identical to that in the EVAL S1 simulation (Jöckel et al., 2006) SCM differs mainly in the vertical resolution of the model, which is most significantly reduced near the tropopause, and the above mentioned change.

The upper part of Table 4 compares the average deposition fluxes from the individual measurement networks with the four simulations.
While for all three components the SCM and COM simulations yield very similar values, the EASY simulation always shows lower deposition fluxes. Replacing the physical with the effective Henry's law coefficients (EASY2) the wet deposition of most species is larger compared to the simulations explicitely calculating aqueous phase chemistry. The higher wet deposition is partly caused by not taking the gas phase diffusion limitation into account, and instead assuming equilibrium between gas and liquid phase. Additionally, the prescribed $\mathrm{pH}$ value of 5, which is in general less acidic in the more polluted regions than in the SCM and COM simulations, leads to an enhanced scavenging.

The underestimation of the EASY setup is most obvious for $\mathrm{NH}_{\mathrm{x}}$ for which we obtain unrealistically low wet deposition fluxes. The failure of the EASY simulation for ammonia can be explained by the highly reduced uptake of gaseous $\mathrm{NH}_{3}$ into the cloud and precipitation droplets due to the relatively low solubility of ammonia and the neglect of the dissociation and neutralisation in water in this setup. For the more soluble compound $\mathrm{HNO}_{3}$ the difference is less obvious. However, due to the neglect of the dissociation the efficient uptake into the droplets is still substantially reduced (EASY). In contrast, with the effective Henry's law coefficients the uptake of the acidic species is overestimated (EASY2), since in the polluted regions the actual $\mathrm{pH}$ is lower than the prescribed value of 5 and the altered oxidation capacity of the atmosphere leads to enhanced $\mathrm{HNO}_{3}$ production. In the EASY simulation sulphate wet deposition only results from the dissolution of sulphuric acid $\left(\mathrm{H}_{2} \mathrm{SO}_{4}\right)$, since liquid phase oxidation of $\mathrm{SO}_{2}$ does not occur. Consequently, sulphur dioxide is only oxidised to $\mathrm{H}_{2} \mathrm{SO}_{4}$ in the gas phase, which only represents a small fraction of this process, and the wet deposition of sulphate is considerably lower in EASY. This is also valid for EASY2, which therefore also underestimates the $\mathrm{S}(\mathrm{VI})$ content in the precipitation water, but removes $\mathrm{SO}_{2}$ from the atmosphere slightly more realistically (cf. Fig. 12). For $\mathrm{NH}_{\mathrm{x}}$ the EASY2 simulation is able to calculate the wet removal from the atmosphere within an acceptable accuracy range compared with the observations, but similar to $\mathrm{HNO}_{3}$ wet deposition is enhanced compared with the observations.

The spatial patterns of the model calculations (represented by the correlation in the lower chart of Table 4) are generally correlated best with the observations for the SCM and COM simulations. For nitrate, the differences are not that large due to the high solubilities of gaseous $\mathrm{HNO}_{3}$ and $\mathrm{N}_{2} \mathrm{O}_{5}$. This becomes more obvious for the less soluble $\mathrm{NH}_{\mathrm{x}}$ species, where the results from the EASY simulation are only weakly correlated to the measurements. The agreement for EASY2 is good for species without irreversible chemistry in the liquid phase. The liquid phase sulphate formation from $\mathrm{SO}_{2}$ scavenging and oxidation cannot be simulated with this approach, therefore resulting in a lower correlation between EASY2 and the observations for sulphate wet deposition.

Concluding, for the wet deposition calculations of the basic species, relevant e.g. for acid rain formation, the 
Table 3. Average annual deposition values for nitrate (in $\mathrm{mg} \mathrm{N} / \mathrm{m}^{2}$ ), sulphate (in $\mathrm{mg} \mathrm{S} / \mathrm{m}^{2}$ ) and $\mathrm{NH}_{\mathrm{x}}$ (in $\mathrm{mg} \mathrm{N} / \mathrm{m}^{2}$ ) from this study and D06 and the corresponding measured values as applied in the respective studies.

\begin{tabular}{|c|c|c|c|c|c|c|c|c|c|c|c|c|}
\hline & \multicolumn{4}{|c|}{ nitrate $\left(\mathrm{mg} \mathrm{N} / \mathrm{m}^{2}\right)$} & \multicolumn{4}{|c|}{ sulphate $\left(\mathrm{mg} \mathrm{S} / \mathrm{m}^{2}\right)$} & \multicolumn{4}{|c|}{$\mathrm{NH}_{\mathrm{X}}\left(\mathrm{mg} \mathrm{N} / \mathrm{m}^{2}\right)$} \\
\hline & \multicolumn{2}{|c|}{ this study } & \multicolumn{2}{|c|}{ D06 } & \multicolumn{2}{|c|}{ this study } & \multicolumn{2}{|c|}{ D06 } & \multicolumn{2}{|c|}{ this study } & \multicolumn{2}{|c|}{ D06 } \\
\hline & model & obs & model & obs & model & obs & model & obs & model & obs & model & obs \\
\hline NADP & 201 & 195 & 227 & 195 & 385 & 321 & 364 & 322 & 148 & 152 & 167 & 151 \\
\hline EMEP & 215 & 303 & 278 & 302 & 364 & 413 & 336 & 412 & 232 & 340 & 347 & 339 \\
\hline EANET & 289 & 331 & 227 & 330 & 467 & 649 & 469 & 648 & 433 & 654 & 519 & 653 \\
\hline IDAF & 215 & 138 & 153 & 131 & 154 & 249 & 119 & 325 & 187 & 214 & 175 & 184 \\
\hline
\end{tabular}

Table 4. Average annual deposition values for nitrate (in $\mathrm{mg} \mathrm{N} / \mathrm{m}^{2}$ ), sulphate (in $\mathrm{mg} \mathrm{S} / \mathrm{m}^{2}$ ) and $\mathrm{NH}_{\mathrm{X}}$ (in $\mathrm{mg} \mathrm{N} / \mathrm{m}^{2}$ ) for the observed values and for the four sensitivity studies (upper table) and correlation of the wet deposition fluxes with the observations for the four sensitivity studies (lower table).

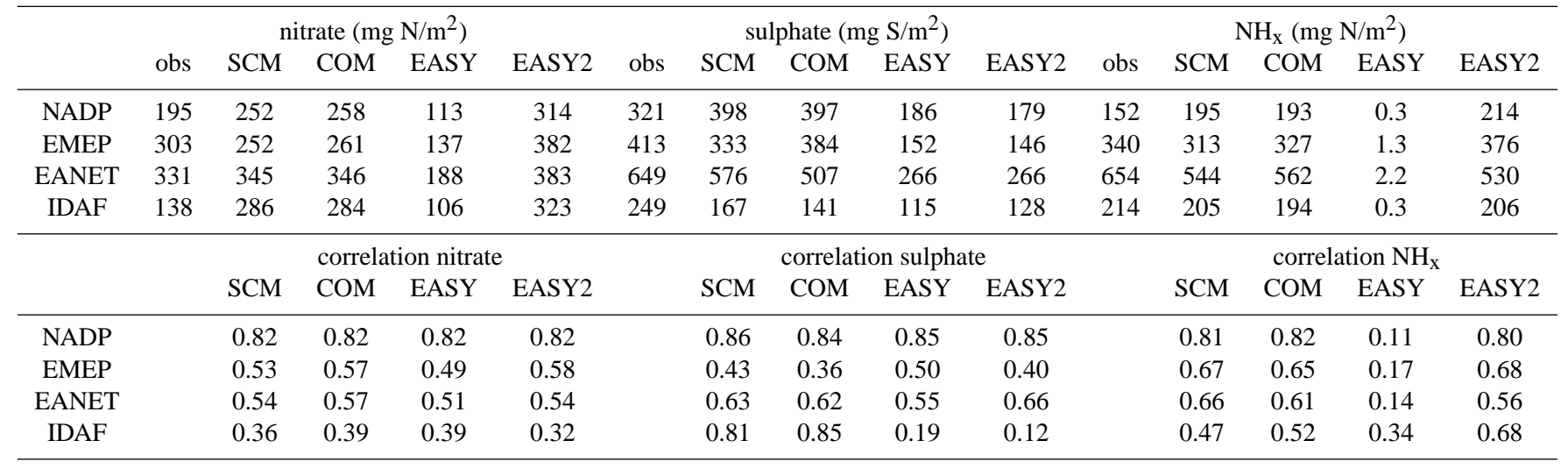

partitioning according to Henry's law alone is not sufficient for atmospheric chemistry modelling. The attempt to partly overcome this limitation by using effective Henry's law coefficients (e.g. Sander, 1999) that account for the dissociation of acidic and alkaline species based on a globally constant $\mathrm{pH}$ value leads to problems, since the $\mathrm{H}_{3} \mathrm{O}^{+}$concentrations in the liquid are highly variable in space and time and $\mathrm{pH}$-dependent reactions such as S(IV) oxidation cannot be parameterised easily. Alternative effective scavenging coefficient formulations applied in other models (e.g. Yin et al., 2001; Asman, 1995), taking some basic chemical reactions into account, are often determined for a specific location. Therefore they cannot be straight-forwardly applied on the global scale, which includes a large range of conditions from highly polluted to remote regions. For example, Mizak et al. (2005) present a different algorithm for $\mathrm{NH}_{3}$ scavenging based on observations compared to Asman (1995). If the dependence on the $\mathrm{pH}$ value is applied to compute the effective Henry's law coefficient correctly as well as the oxidant concentrations for basic chemistry (dependent on time and the location), these quantities must be determined appropriately by taking all relevant aqueous phase species and reactions into account, which in turn is slightly more computationally expensive and finally results in a system of coupled differential equations as it is applied in the SCM or COM simulation setup.

\section{2 $\mathrm{pH}$ value of clouds and precipitation}

As a consequence of the comprehensive treatment of dissociation reactions in the liquid phase and the coupling of all reactions that affect the solution ion balance, the cloud and precipitation $\mathrm{pH}$ can be calculated directly during each time step. The initial $\mathrm{pH}$ of the droplets (cloud and precipitation) is determined from the dissolved species, i.e. the ions originating from scavenged aerosol particles and the influx from layers above (for precipitation). In contrast to previous studies we do not apply assumptions about the dissociated fraction of components nor do we prescribe oxidant concentrations. The latter is associated with difficulties for oxidants that are significantly affected by aqueous phase reactions, e.g. $\mathrm{H}_{2} \mathrm{O}_{2}$. For the comparison with measurement data, the aqueous phase $\mathrm{H}_{3} \mathrm{O}^{+}$concentrations are averaged and weighted with the amount of liquid water for precipitation and clouds, and the results presented are based on our most comprehensive simulation (COM).

The left panel of Fig. 5 depicts the annual average precipitation $\mathrm{pH}$ at the surface, originating from both convective and large-scale rainfall, weighted with the amount of rainwater 

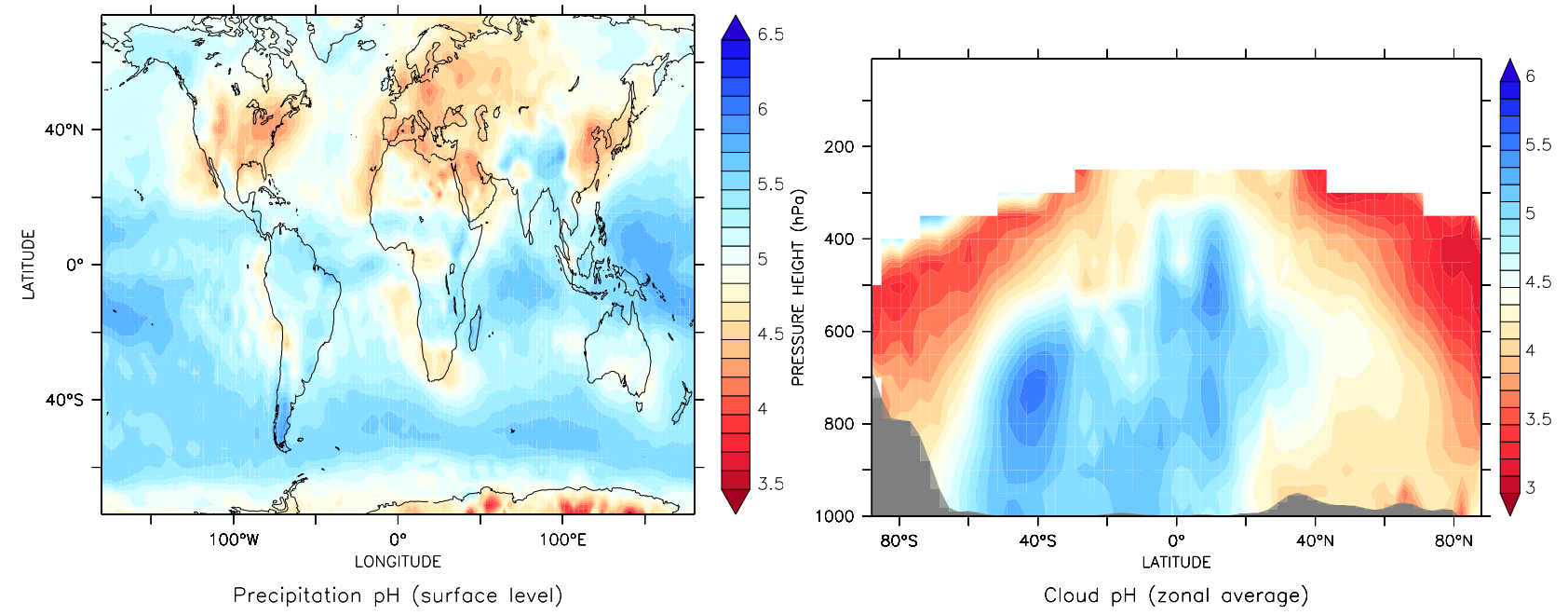

Fig. 5. Annual average precipitation $\mathrm{pH}$ at the surface from large-scale and convective precipitation (left) and annual zonal average of the cloud $\mathrm{pH}$ (right).

and the fraction of the precipitation type. The precipitation $\mathrm{pH}$ varies between values around 3.5 and 6.5 , being always in the acidic regime due to the atmospheric $\mathrm{CO}_{2}$. Highest $\mathrm{pH}$ values are found over the tropical oceans where pollution sources are small and precipitation rates are high. This is also valid for other regions where pollution is low. In some regions the neutralising effect of ammonia plays a significant role, e.g over India, mainly neutralising the nitric acid produced from intense $\mathrm{NO}_{\mathrm{x}}$ emissions. The alkaline compounds of sea salt and mineral dust are neglected in this study, because the ionic composition of these aerosol types is not yet considered in the aerosol submodel M7.

Therefore, the relatively high $\mathrm{pH}$ values in the southern storm tracks result mainly from being far from pollution sources. Over the tropical continents, especially Central Africa, the relatively low $\mathrm{pH}$ is mostly a result of the $\mathrm{NO}_{\mathrm{x}}$ emissions by biomass burning. In several desert regions, e.g. in Africa, the $\mathrm{pH}$ can be rather low, mainly due to the small total amount of cloud and rain water, which concentrates the available acidity. In Europe, China and the eastern USA strong anthropogenic emissions of $\mathrm{SO}_{2}$ and $\mathrm{NO}_{\mathrm{x}}$ reduce the $\mathrm{pH}$ of clouds and precipitation, only partly compensated by the dissolution of ammonia.

As mentioned earlier, the comparison with observations can only give indications to what extent the main features and average $\mathrm{pH}$ ranges are captured by the model. The calculated $\mathrm{pH}$ values are compared with observed precipitation $\mathrm{pH}$ for the year 2000 in the USA with data from the NADP network (figures in Sect. 2 in the supplement). Even though the main features, e.g., the east-west gradient, are captured well, the correlation is moderate $(R \approx 0.65)$ and some of the fine structures apparent from the relatively dense network are not resolved. Furthermore, the east-west gradient in the USA is stronger in the observations with values larger than 5 in the western and central USA, where the model results indicate too acidic precipitation. This may partly result from a slight underestimation of the total precipitation, especially in the Central USA, but mostly an overestimation of the $\mathrm{H}_{3} \mathrm{O}^{+}$ concentrations. Since sulphate, nitrate and ammonium deposition are calculated accurately, we suspect a contribution by mineral cations in wind blown dust and alkaline sea salt, not included in our model setup.

For Europe we use the data collected in the EMEP/CCC Report $1 / 2006^{8}$, and the comparison with the simulation indicates general agreement with precipitation $\mathrm{pH}$ distributions; however, the model is often slightly too acidic. This is partly a consequence of the underestimate of dissolved $\mathrm{NH}_{\mathrm{x}}(\mathrm{Ta}-$ ble 3). Even though the precipitation distribution in general is captured quite accurately by the model (Hagemann et al., 2006; Tost et al., 2006b) the local variability at specific measurement stations can show substantial differences compared to the model grid box average, which affects the rain water $\mathrm{pH}$. Safai et al. (2004) use a compilation of $\mathrm{pH}$ samples for India with average values between 5.3 and 7.7, in relatively good agreement with the model simulated results. Additionally, data by Aikawa et al. (2001) with average precipitation $\mathrm{pH}$ values of 4.7 correspond to the simulation results for Japan.

The right panel of Fig. 5 depicts the annual and zonal average of cloud $\mathrm{pH}$. Above $250 \mathrm{hPa}$ in the tropics to $400 \mathrm{hPa}$ at the poles the liquid water content of the clouds is too small to calculate cloud chemistry, and therefore $\mathrm{pH}$ calculations have little meaning, since the clouds consist mainly of ice. The grey shaded area near the lower boundary represents the zonal mean surface orography. The highest $\mathrm{pH}$ values are found in the convective regions of the tropics and

\footnotetext{
${ }^{8}$ available from: http://www.nilu.no/projects/ccc/reports.html
} 
in the southern hemisphere storm tracks. The figure shows that the deep convective towers are less acidic due to the high water content and the remoteness from acidic emissions compared to the mid-latitudes. Furthermore the composite of large-scale and convective clouds in the southern storm tracks shows a pH maximum at about $700 \mathrm{hPa}$, where the liquid water content (LWC) is typically highest, and these regions are also remote from acid precursor emissions. In the northern hemisphere the clouds are much more acidic from the surface up to $700 \mathrm{hPa}$ due to anthropogenic emissions of $\mathrm{SO}_{2}$ and $\mathrm{NO}_{\mathrm{x}}$. The $\mathrm{pH}$ values slightly increase toward 600$700 \mathrm{hPa}$ related to the maximum LWC. The convective activity north of $40^{\circ} \mathrm{N}$ coincides with slightly lower $\mathrm{pH}$ values at about $800 \mathrm{hPa}$ compared to the subtropical regions further south where subsidence is dominant. At higher altitudes and further poleward in both hemispheres the clouds are increasingly frozen, thus reducing the cloud LWC. Therefore the relatively small amounts of $\mathrm{HNO}_{3}$ or $\mathrm{H}_{2} \mathrm{SO}_{4}$ lead to stronger acidification under these conditions. However, it should be mentioned that the convective cloud $\mathrm{pH}$ is partly too low because we do not use the total convective cloud water for the scavenging calculations but rather the fraction that produces precipitation, since the total cloud water is not directly accessible from the currently used convection parameterisation due to a highly simplified cloud microphysics.

Measurements of $\mathrm{pH}$ values in clouds result mainly from hill cap clouds and fog at elevated observatories. Marinoni et al. (2004) measured levels mainly between 4.5 and 5.5 at a remote site in France, but note that there are local $\mathrm{NH}_{\mathrm{x}}$ sources. However, at the same site values between $4.1 \pm 0.5$ and 5.7 \pm 0.1 also occur (Sellegri et al., 2003), indicating the high variability. Moore et al. (2004) report $\mathrm{pH}$ values for New York between 2.7 and 3.7, thus highly acidic. Of course, such acidic values do not appear in the zonal average, but close to the surface in polluted areas (such as the eastern USA) a similar $\mathrm{pH}$ range is calculated by the model.

The $\mathrm{pH}$ distribution of the simplified aqueous phase mechanism (SCM) results in similar patterns. However, these are not identical due to the additional chemical processes in the liquid phase and the feedback via the gas phase (cf. Section 4.3). Since in the EASY simulation dissociation reactions in the liquid do not take place, a $\mathrm{pH}$ value cannot be determined, whereas in EASY2 it is prescribed to calculate the effective Henry's law coefficients.

\subsection{Influences of cloud and precipitation chemistry on gas phase constituents}

To analyse the influence of comprehensive aqueous phase chemistry on gas phase constituents, the sensitivity simulations described in Sect. 3 are compared for several gas phase species, using the COM simulation as a reference and showing absolute differences to this reference for the other simulations. Furthermore, we evaluate which simulations agree best with the observational data compiled by Emmons et al. (2000, and references therein $)^{9}$. For these comparisons only four selected locations are presented here, i.e. from the TOPSE (Atlas et al., 2003) and TRACE-P (Jacob et al., 2003) campaigns, because these measurements approximately coincide with the period for which the applied emission data are representative. We provide additional comparisons with previous campaigns in the electronic supplement (http://www.atmos-chem-phys.net/7/ 2733/2007/acp-7-2733-2007-supplement.pdf). The general evaluation of the tropospheric and stratospheric chemistry in ECHAM5/MESSy1 has been presented by Jöckel et al. (2006) and Pozzer et al. (2007). Due to the coupling of gas phase chemistry with the cloud and precipitation chemistry we expect direct and indirect effects resulting from a different treatment of the aqueous phase chemistry. It should be noted that the terms of direct and indirect effects used here may not be mistaken for direct and indirect aerosol effects on climate. The direct effect in this study is caused by a difference in the uptake into the droplets which depends on the process formulation and the concentration in the liquid phase. Furthermore, the consideration of various chemical reactions in the liquid may also be conceived as a direct effect. The direct effects are especially important for the species participating in comprehensive aqueous phase chemical reactions, e.g., $\mathrm{SO}_{2}$ conversion to $\mathrm{SO}_{4}^{2-}$ in the droplets by $\mathrm{H}_{2} \mathrm{O}_{2}$ and $\mathrm{O}_{3}$, dependent on the $\mathrm{pH}$. Additionally, $\mathrm{pH}$ dependent acid-base equilibria are associated with changes in liquid concentrations, if more species are considered.

Furthermore, a different chemical composition of the atmosphere resulting from cloud and precipitation chemistry modifies the oxidation capacity of the atmosphere, which indirectly alters the mixing ratios of chemically active trace constituents. This is shown by the $\mathrm{OH}$ distributions in the supplement (Sect. 4.1, http://www.atmos-chem-phys.net/7/ 2733/2007/acp-7-2733-2007-supplement.pdf). Even though the mixing ratio differences to the reference simulation are relatively small, they indicate that the net turnover of hydroxyl radicals can increase substantially.

An additional aspect of even higher significance is the modified vertical transport behaviour in convective clouds. In case of a weaker scavenging due to less efficient uptake into the droplets, species with high mixing ratios at the surface are more efficiently transported into the upper troposphere, where they can alter the chemical reaction pathways.

For a more detailed analysis in addition to the near surface mixing ratios the annual zonal average mixing ratios can be found in the supplement, as well as figures comparing the total global tracer mass. Since the NOSCAV simulation is unrealistic, because of the neglected scavenging and wet deposition, these respective figures have been transferred to the supplement.

\footnotetext{
${ }^{9}$ updated dataset obtained from: http://acd.ucar.edu/ emmons/ DATACOMP/camp_table.htm
} 


\subsubsection{Nitric Acid $\left(\mathrm{HNO}_{3}\right)$}

The surface mixing ratio of $\mathrm{HNO}_{3}$ in the COM simulation, depicted in the upper left panel of Fig. 6, shows highest values in regions with strong $\mathrm{NO}_{\mathrm{x}}$ emissions caused by the rapid chemical transformation of $\mathrm{NO}_{2}$ by $\mathrm{OH}$ during daylight and heterogeneous removal of $\mathrm{N}_{2} \mathrm{O}_{5}$ during night time. The $\mathrm{NO}_{\mathrm{x}}$ emissions by industry and traffic (Europe, USA, China, partly India), soil emissions (tropical rain forests), biomass burning (e.g. Central Africa), all significantly contribute to the surface mixing ratios of $\mathrm{HNO}_{3}$. Lightning as a $\mathrm{NO}_{\mathrm{x}}$ source is more important in the upper troposphere. Scavenging and subsequent wet deposition is the main sink of $\mathrm{HNO}_{3}$, being much more efficient than dry deposition and photodissociation. In the SCM simulation (upper right panel of Fig. 6) similar nitric acid mixing ratios near the surface are computed. Only in the eastern USA and Europe slightly higher values are calculated, whereas almost everywhere else the differences to COM are rather small. The differences mainly result from the indirect effects (higher $\mathrm{NO}_{\mathrm{x}}$ mixing ratios (see supplement) due to the neglect of scavenging of $\mathrm{HONO}$ and $\mathrm{HNO}_{4}$ in $\mathrm{SCM}$ ) and to a lesser extent from interactions with sulphur compounds in the aqueous phase.

The reduced scavenging in EASY, neglecting the dissociation of $\mathrm{HNO}_{3}$ in the liquid, leads to higher near-surface mixing ratios worldwide. However, due to the high solubility an important fraction of nitric acid is nevertheless scavenged and removed from the atmosphere by wet deposition. The largest differences occur in the regions with highest overall mixing ratios, emphasising the underestimation of precipitation loss by simplified scavenging, whereas in regions remote from the sources the differences are mostly small. Nevertheless, in this simulation the nitric acid is on average substantially higher than in the other setups. The near surface mixing ratios in the EASY2 simulation are very close to those of COM (lower right panel of Fig. 6). This emphasises that the concept of effective Henry's law coefficients is in general applicable for species that mainly dissociate and are only of minor importance for aqueous phase chemistry. The assumed $\mathrm{pH}$ of 5 is within the range of that expected (varying from 3.5 to 6, cf. Fig. 5). Thus the scavenging of nitric acid, which almost completely dissociates into nitrate above a $\mathrm{pH}$ value of 1 , is approximated sufficiently well. On the other hand it should be noted that, even though the near surface mixing ratios and also the zonal average distribution of gaseous nitric acid in EASY2 are very close to the COM setup, the nitrate wet deposition in EASY2 is substantially higher than in COM and the observations (cf. Table 4). Additionally, the dry deposition of $\mathrm{HNO}_{3}$ is larger in the EASY2 setup, both indicating that due to the altered oxidation capacity in EASY2 more $\mathrm{HNO}_{3}$ is produced and subsequently removed by dry and wet deposition.

In the NOSCAV simulation almost everywhere unrealistically enhanced $\mathrm{HNO}_{3}$ mixing ratios are calculated near the surface (see supplement Sect. 5, panel c). In regions with strong sources the differences are largest, although they propagate over large distances due to the enhanced lifetime. Compared to EASY, the absolute values of the differences to $\mathrm{COM}$ are slightly smaller resulting from the more efficient vertical transport due to the neglect of depletion by clouds and precipitation. The global mass of nitric acid is very similar for COM, SCM and EASY2, showing that the sink process of wet removal is simulated acceptably with the simplified chemistry, whereas EASY and - much worse - NOSCAV substantially overestimate the $\mathrm{HNO}_{3}$ content of the atmosphere.

The calculated $\mathrm{HNO}_{3}$ mixing ratios for TOPSE and TRACE-P for both the COM and SCM simulations are well within the range of the observations (Emmons et al., 2000), whereas EASY and much worse NOSCAV strongly overestimate the $\mathrm{HNO}_{3}$ mixing ratios. In EASY2 the $\mathrm{HNO}_{3}$ values are only slightly higher than in COM and SCM. The computed vertical distributions typically indicate a $\mathrm{C}$-shape profile resulting from the $\mathrm{NO}_{\mathrm{x}}$ emissions at the surface and downward transport of $\mathrm{HNO}_{3}$ from the stratosphere. Since the vertical resolution in the tropopause region in the L31 model configuration is relatively coarse, cross-tropopause transport is not represented as well as in the L90 setup of Jöckel et al. (2006), leading to an overestimation of the influx into the troposphere from above. Since no upper boundary condition for $\mathrm{NO}_{\mathrm{x}}, \mathrm{HNO}_{3}$ or $\mathrm{O}_{3}$ has been applied, which would mask some of the effects of the cloud chemistry due to enhanced influx from this boundary, the poor representation of the stratosphere and its chemical structure is mainly responsible for the overestimation near the tropopause. For the TRACE-P measurements, in regions where the tropopause is located at higher altitudes and the stratospheric influence at $12 \mathrm{~km}$ altitude is less important, this C-shape is less evident.

For nitric acid, being hardly chemically active in the liquid phase, except for its almost complete dissociation, the atmospheric content and the wet deposition can be simulated with simplified chemistry as well as with an effective Henry's law equilibrium.

\subsubsection{Ozone $\left(\mathrm{O}_{3}\right)$}

Figure 8 presents the annual average surface mixing ratio of ozone of the COM simulation in the upper left panel. The results from the COM simulation near the surface are very close to those presented in the $\mathrm{O}_{3}$ evaluation by Jöckel et al. (2006), showing relatively high mixing ratios in California (e.g. Jacobson, 2005), the Mediterranean region (e.g. Lelieveld et al., 2002), around the Persian Gulf (resulting from high propane emissions), northern India and the Himalayas (the latter associated with the strong surface elevation). The absolute differences between the SCM and COM simulations, depicted in the upper right panel of Fig. 8, mostly result from indirect effects, in particular via the removal of nitrogen oxides. Nevertheless, direct chemical effects through reduced $\mathrm{O}_{3}$ formation and enhanced $\mathrm{O}_{3}$ 
(a) $\mathrm{HNO}_{3}$ surface layer

mixing ratio $(\mathrm{nmol} / \mathrm{mol})(\mathrm{COM})$

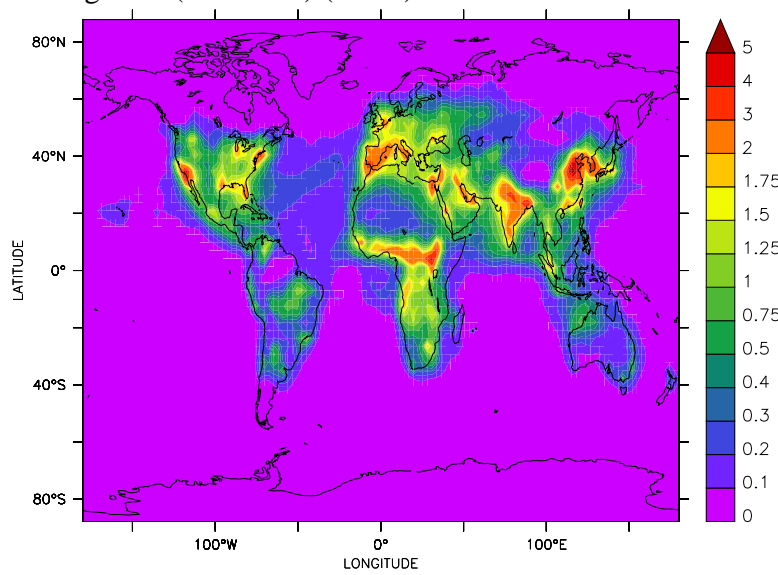

(c) absolute difference

(nmol/mol) (EASY-COM)

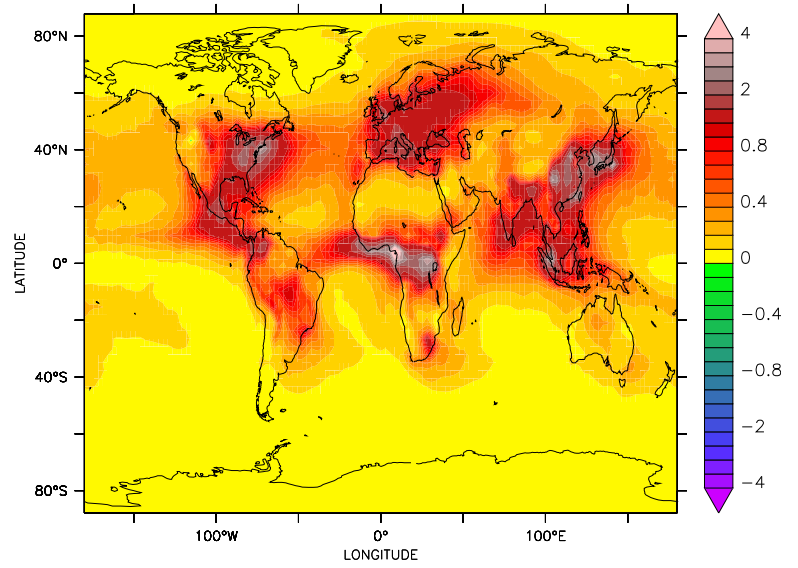

(b) absolute difference

(nmol/mol) (SCM-COM)

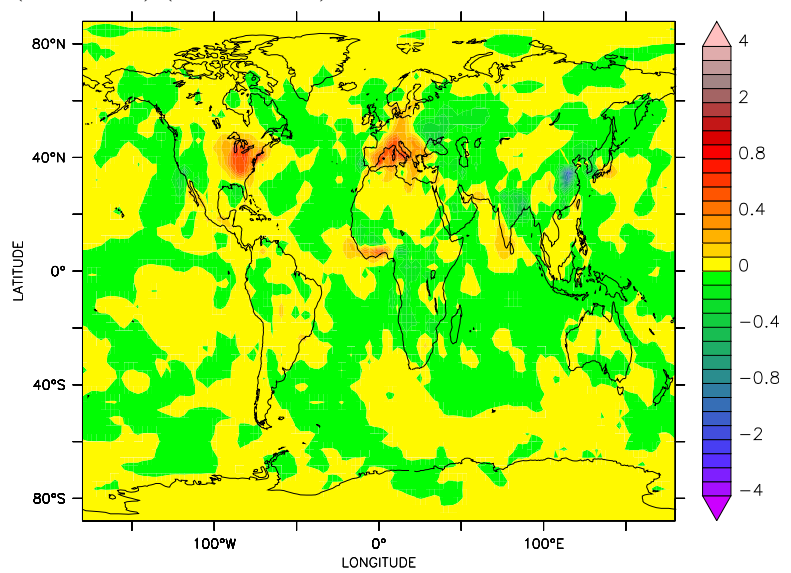

(d) absolute difference

(nmol/mol) (EASY2-COM)

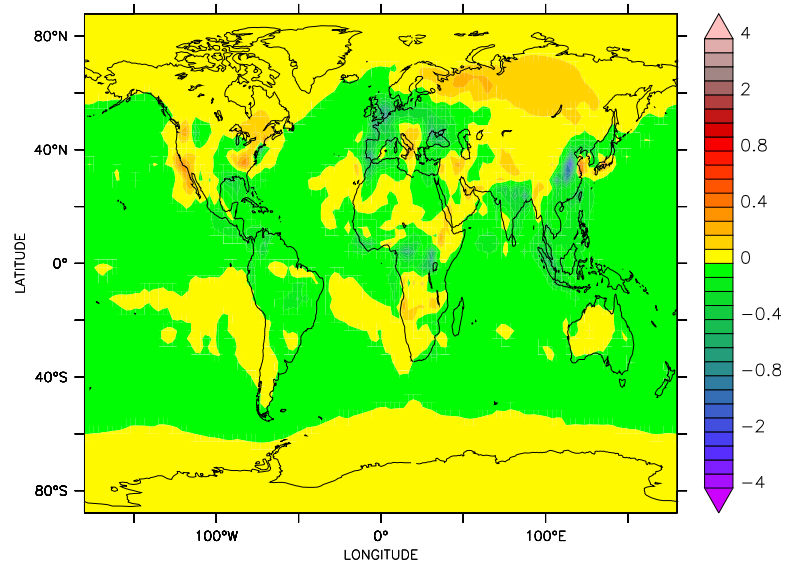

Fig. 6. Comparison of the annual average $\mathrm{HNO}_{3}$ surface layer mixing ratio for the four sensitivity simulations: shown is the absolute value for the COM simulation (upper left panel) and - as indicated - the absolute differences of the other simulations to the COM simulation.
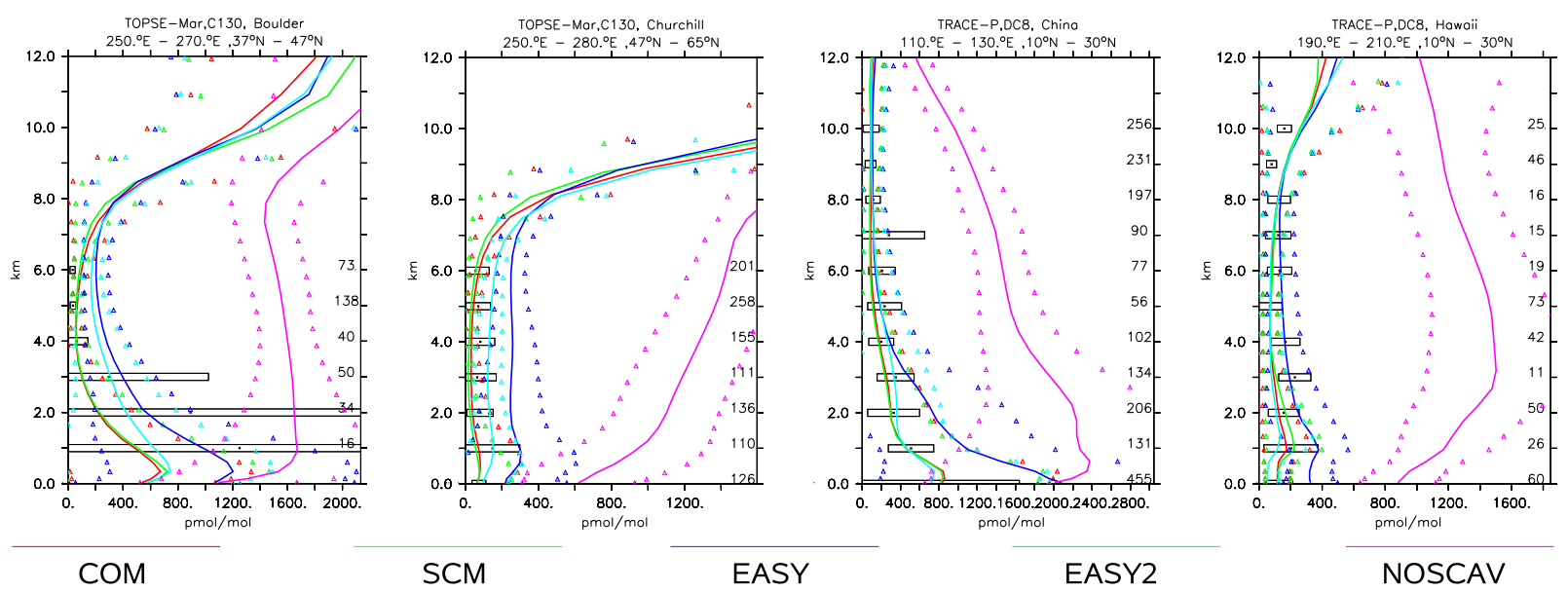

Fig. 7. Comparison of the $\mathrm{HNO}_{3}$ vertical profiles compiled by Emmons et al. (2000) with the results of the five sensitivity simulations. The observations are depicted by the black points, their variability (standard deviation) by the black boxes and the number of points taken into account for this campaign (in space and time for this region) are listed at the right axis. The model results are represented by the solid lines and the respective standard variation by the triangles. The colours denote the simulations as indicated in the legend, i.e., red = COM, green $=\mathrm{SCM}$, blue $=$ EASY, turquoise $=$ EASY2 and magenta $=$ NOSCAV . 
(a) $\mathrm{O}_{3}$ surface layer mixing ratio $(\mathrm{nmol} / \mathrm{mol})(\mathrm{COM})$

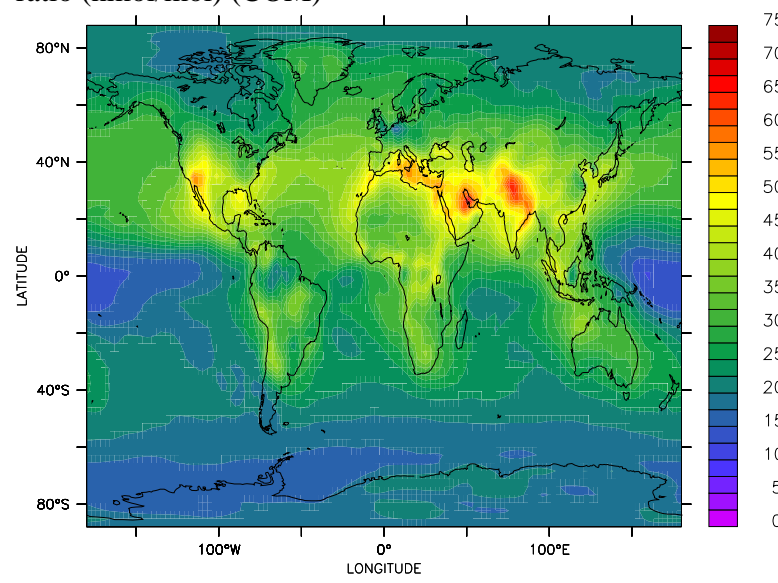

(c) absolute difference (nmol/mol) (EASY-COM)

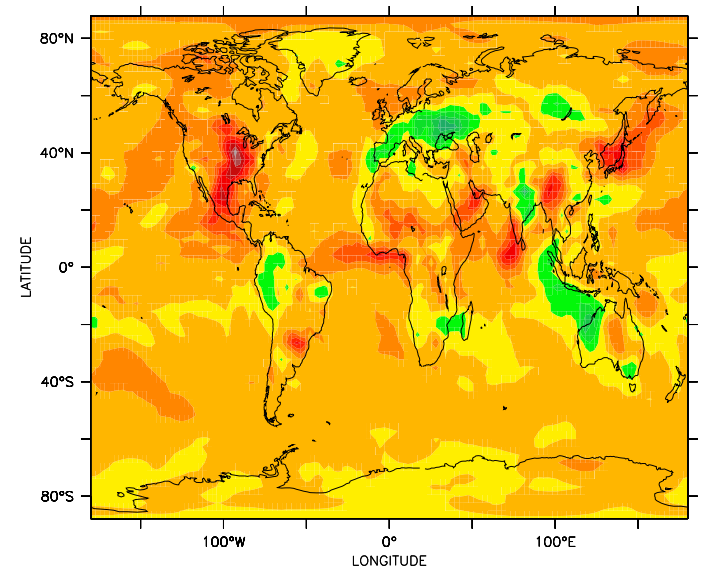

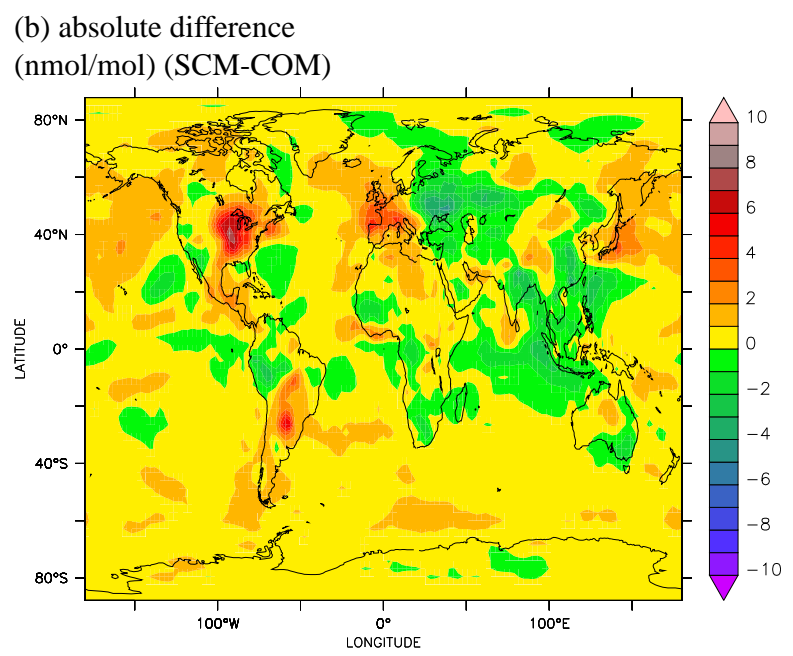

(d) absolute difference (nmol/mol) (EASY2-COM)

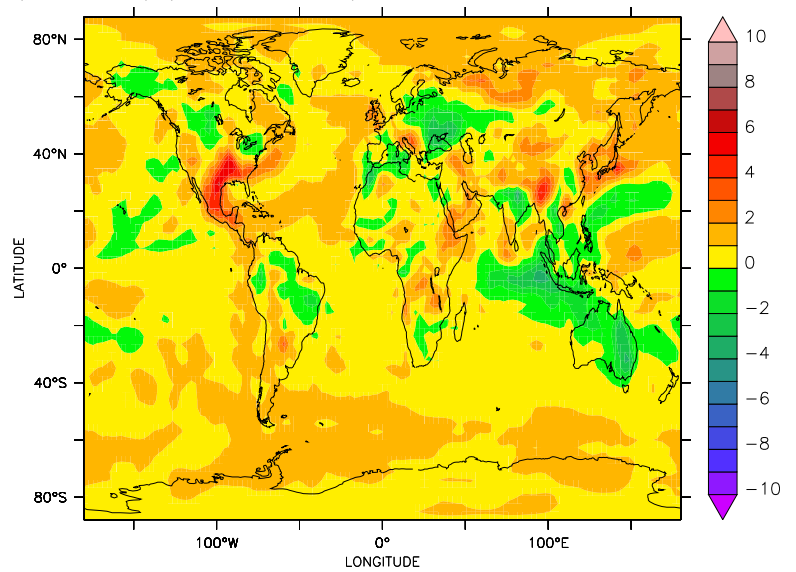

Fig. 8. Comparison of the annual average $\mathrm{O}_{3}$ surface layer mixing ratio for the four sensitivity simulations, displayed similarly as in Fig. 6 .
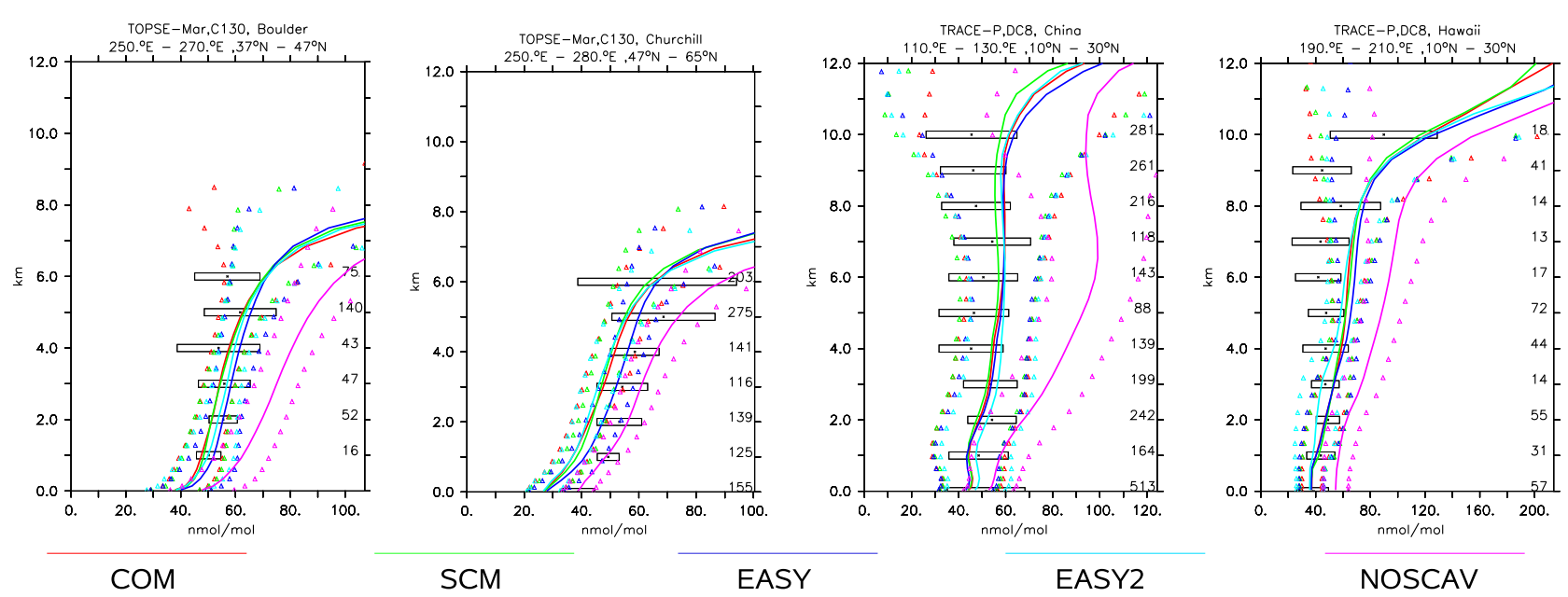

Fig. 9. As Fig. 7, but for $\mathrm{O}_{3}$. 
destruction in clouds play a secondary role over parts of the eastern USA, western Europe, South America and near Japan. On the other hand, in eastern Europe and near Indonesia and the Indian Ocean detailed cloud chemical processes enhance ozone mixing ratios near the surface, mostly because chemical destruction pathways of $\mathrm{O}_{3}$ are reduced. The indirect effects of the cloud chemistry result mainly from the modified $\mathrm{NO}_{\mathrm{x}}$ mixing ratios. Consequently, the ozone production from $\mathrm{NO}_{\mathrm{x}}$ (ProdNo, shown in the supplement) is altered: in regions where the modified scavenging/cloud chemistry formulation leads to enhanced $\mathrm{NO}_{\mathrm{x}}$ also enhanced $\mathrm{O}_{3}$ is found and vice versa. The influence of aqueous phase chemistry on the other major ozone production and destruction rates is lower. The ozone mixing ratios computed in the EASY simulation are predominantly higher than in COM, largely resulting from the less efficient removal of $\mathrm{O}_{3}$ precursor gases. This results in relative increases of up to about $20 \%$ at some locations, as shown in the lower left panel of Fig. 8, whereas in Europe and near Indonesia the reduction of $\mathrm{O}_{3}$ loss is more important. With the effective Henry's law equilibrium in EASY2 (lower right panel of Fig. 8) the differences to COM are much smaller than in EASY, but overall slightly more $\mathrm{O}_{3}$ is simulated in the surface layer, again resulting mainly from indirect effects. The simulation without cloud processes and scavenging (NOSCAV) generally results in much higher and unrealistic $\mathrm{O}_{3}$ mixing ratios throughout the troposphere, resulting from the drastically altered concentrations and distributions of precursor gases. Unquestionably, the cloud and precipitation related chemistry and removal processes yield much reduced oxidant levels in the gas phase.

Figure 9 presents a comparison of model results with aircraft observations. From the TOPSE measurements an increase of $\mathrm{O}_{3}$ mixing ratios with altitude near the tropopause illustrates the influence of stratospheric $\mathrm{O}_{3}$. For the lower and middle troposphere the COM, SCM, EASY2 and EASY simulations produce rather similar results, being close to the measurements, while the EASY results for $\mathrm{O}_{3}$ are systematically higher. The NOSCAV simulation strongly overestimates $\mathrm{O}_{3}$ mixing ratios throughout the troposphere, and is unable to reproduce the observations. In general, the observations are reproduced quite accurately by the COM and SCM simulations, although for Hawaii all simulations overestimate $\mathrm{O}_{3}$, with $\mathrm{COM}$ and SCM being slightly lower. In the upper troposphere in the model the influence of the stratosphere appears to be too strong, resulting from an overestimated transport into the troposphere due to the coarse vertical resolution. Jöckel et al. (2006) show that this process is simulated quite realistically using the model configuration with enhanced vertical resolution near the tropopause (90 vertical levels).

\subsubsection{Hydrogen peroxide $\left(\mathrm{H}_{2} \mathrm{O}_{2}\right)$}

Hydrogen peroxide $\left(\mathrm{H}_{2} \mathrm{O}_{2}\right)$ efficiently dissolves into the liquid phase, where it can oxidise S(IV) and is removed from the atmosphere by precipitation. Because of the much lower solubility of $\mathrm{OH}, \mathrm{NO}_{3}$ and other oxidants, it is a main oxidant in the liquid phase. The oxidation reactions represent an additional chemical sink of this compound in clouds and precipitation.

This is illustrated in Fig. 10, in which the annual average surface mixing ratio of $\mathrm{H}_{2} \mathrm{O}_{2}$ is displayed for the COM simulation (upper left panel). Relatively high values occur over the tropical rainforest regions, associated with abundant NMHC oxidation with high yields of the main precursor of hydrogen peroxide, i.e., hydroperoxy radicals $\left(\mathrm{HO}_{2}\right)$. Toward the poles a strong negative gradient is evident, related to both the lower NMHC emissions and lower photochemical activity. In the upper right panel with the reduced chemical mechanism (SCM) higher values than in COM are calculated in the tropics. Since in this setup the photolysis of $\mathrm{H}_{2} \mathrm{O}_{2}$ in the aqueous phase, representing a chemical loss process, is neglected, the liquid phase concentrations are higher than in COM and the uptake into droplets is less efficient. In eastern Europe the mixing ratio near the surface in SCM is lower than in COM, resulting mainly from the altered chemical composition (indirect effect), whereas in the polar regions with low mixing ratios the absolute differences are small. The indirect effect results mainly from the enhanced ozone mixing ratios, producing more $\mathrm{OH}$ and $\mathrm{HO}_{2}$, and consequently more $\mathrm{H}_{2} \mathrm{O}_{2}$.

The lower left panel, presenting the EASY simulation, in which the liquid phase oxidation of $\mathrm{SO}_{2}$ is additionally neglected, the differences are larger. In the polluted regions of the northern hemisphere (eastern USA, western Europe, China) substantially higher $\mathrm{H}_{2} \mathrm{O}_{2}$ mixing ratios are calculated due to this neglect. The EASY2 simulation shows very similar average near surface mixing ratios for $\mathrm{H}_{2} \mathrm{O}_{2}$, since the processes in which hydrogen peroxide is involved are almost identical. This results in a comparable distribution as in EASY. However, especially over China in both model setups based on a Henry's law equilibrium substantially higher $\mathrm{H}_{2} \mathrm{O}_{2}$ mixing ratios are calculated due to the missing $\mathrm{SO}_{2}$ oxidation.

The vertical distribution for the five simulations (Sect. 6.1 of the supplement) shows highest differences close to the surface in the tropics. In the middle troposphere these differences are smaller, and in the upper troposphere they are hardly discernable for SCM, EASY or EASY2. This is mainly based on the $\mathrm{H}_{2} \mathrm{O}_{2}$ photolysis in the gas phase which becomes more efficient with altitude. However, close to the surface the photolysis in the liquid phase has substantial effects producing the lower mixing ratios in the COM simulation compared to the sensitivity studies. Due to the vertical mixing in the troposphere, the higher mixing ratios of the 
(a) $\mathrm{H}_{2} \mathrm{O}_{2}$ surface layer mixing ratio $(\mathrm{nmol} / \mathrm{mol})(\mathrm{COM})$

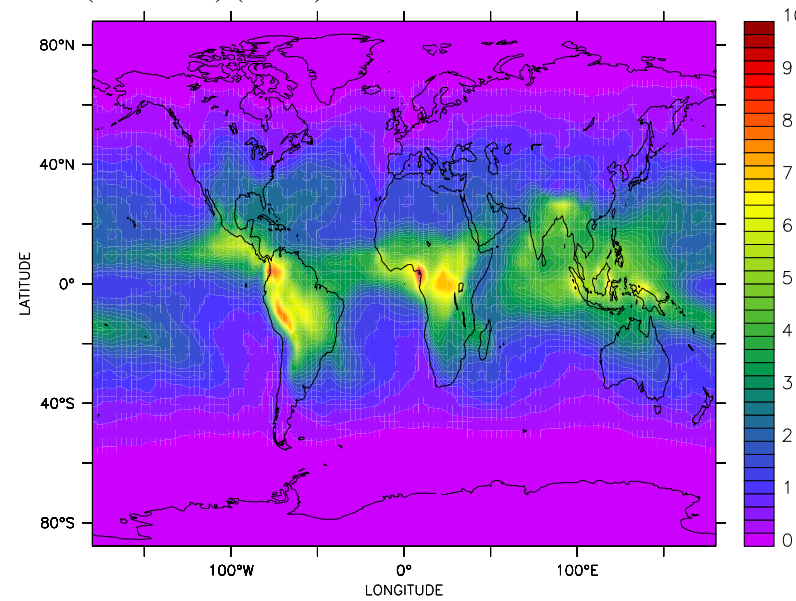

(c) absolute difference

(nmol/mol) (EASY-COM)

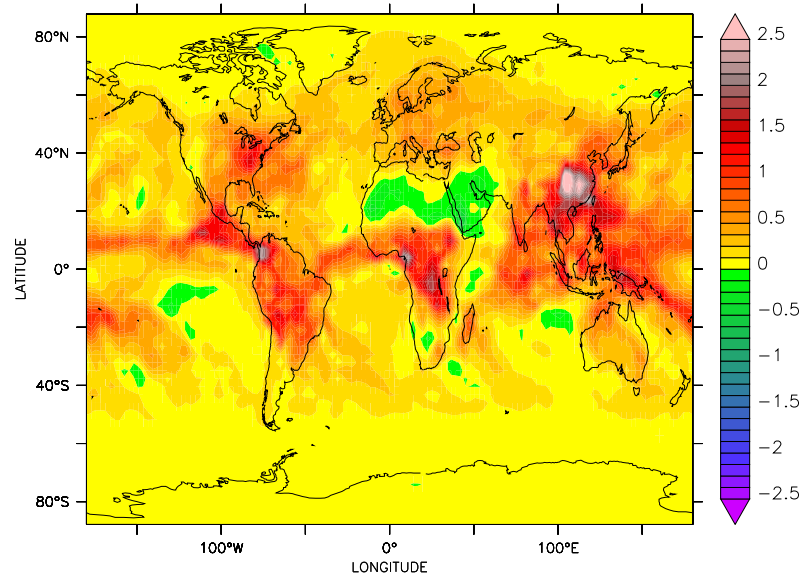

(b) absolute difference

(nmol/mol) (SCM-COM)

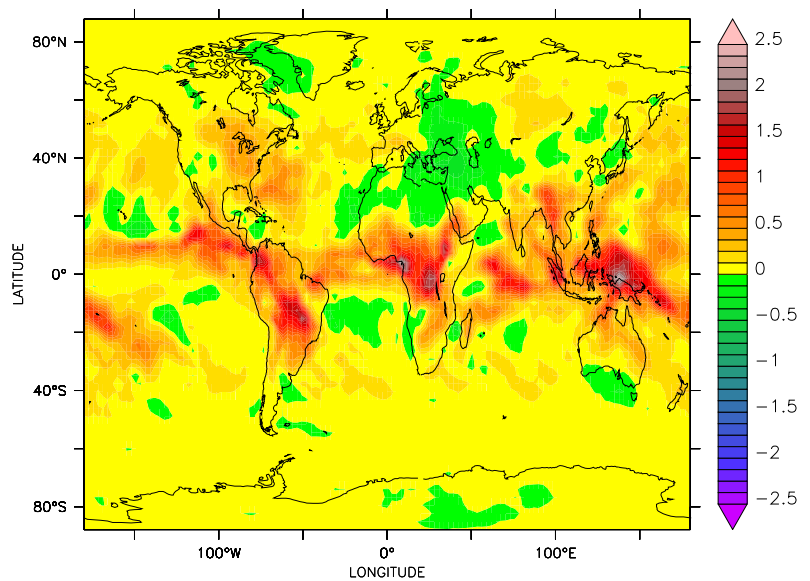

(d) absolute difference

(nmol/mol) (EASY2-COM)

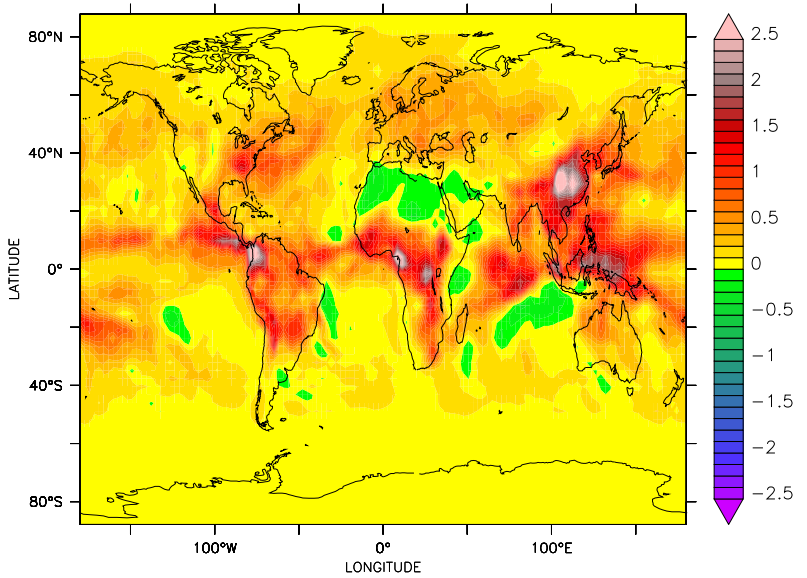

Fig. 10. Comparison of the annual average $\mathrm{H}_{2} \mathrm{O}_{2}$ surface layer mixing ratio for the four sensitivity simulations, displayed similarly as in Fig. 6.
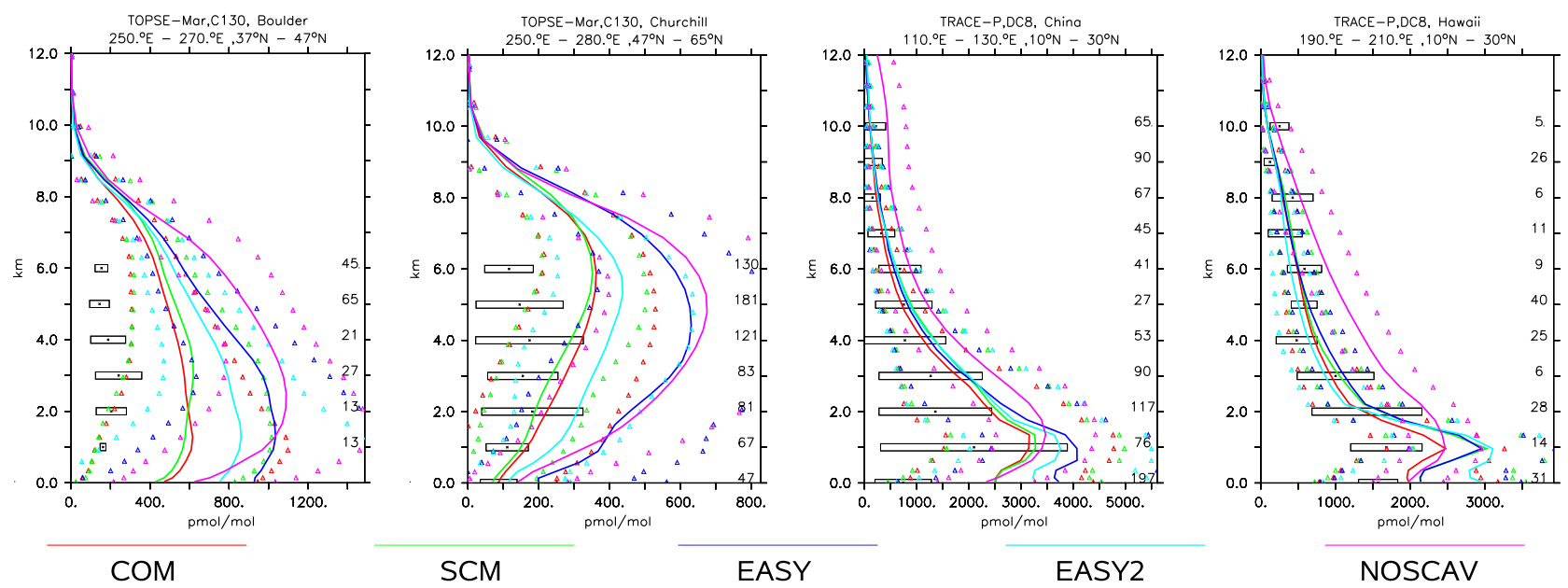

Fig. 11. As Fig. 7, but for $\mathrm{H}_{2} \mathrm{O}_{2}$. 
sensitivity studies are transported upwards into the middle troposphere as mentioned above.

In the NOSCAV simulation (see Sect. 5 of the supplement), the missing sink of wet deposition leads to slightly higher mixing ratios compared to the reference in the polar and the marine subsidence regions, whereas in almost all other locations the values are lower (most obvious over the tropical continents, but also over parts of the oceans, e.g., the SPCZ). These regions are strongly influenced by convective activity, in which the missing wet removal results in an enhanced upward transport into the upper troposphere which is not balanced by downward transport within the aqueous phase. The vertical distribution (see supplement) indicates higher mixing ratios by more than $50 \%$ compared to the COM simulation.

Additionally, among the indirect effects it must be considered that over the tropical continents the simplified and therefore underestimated wet removal results in higher mixing ratios of organic compounds. These species can partly deplete $\mathrm{OH}$ and $\mathrm{HO}_{2}$ by oxidation processes (e.g., since $\mathrm{CH}_{3} \mathrm{OOH}$ is not scavenged in NOSCAV the $\mathrm{HO}_{\mathrm{x}}$ mixing ratios are reduced (see reactions G4107 and G4103 in supplement). In case of a complete neglect of scavenging those effects are even stronger. Consequently, less $\mathrm{H}_{2} \mathrm{O}_{2}$ is formed from the self reaction of $\mathrm{HO}_{2}$. Due to the low $\mathrm{NO}_{\mathrm{x}}$ mixing ratios in these remote regions a recycling of the oxidants is not as efficient as in the polluted regions of the northern hemisphere. Consequently, the total global mass of $\mathrm{H}_{2} \mathrm{O}_{2}$ is by far highest in NOSCAV throughout the middle and upper troposphere, whereas EASY, EASY2 and SCM calculate a similar atmospheric burden. Since all sensitivity simulations with simplified cloud and precipitation chemistry calculate higher mixing ratios of $\mathrm{H}_{2} \mathrm{O}_{2}$, this compound contributes to enhanced $\mathrm{OH}$ production through its photodissociation in the gas phase, and therefore accelerates the gas phase chemistry (contributing through indirect effects).

This is also supported by the comparison with observations in Fig. 11. The vertical profiles for COM and SCM are very similar for the TOPSE campaign. EASY2 shows slightly enhanced mixing ratios, whereas EASY and NOSCAV result in substantially higher values. However, close to the surface in NOSCAV nearly comparable low values are calculated. For the TRACE-P data in China and Hawaii, COM is slightly lower than SCM. The EASY simulation is characterised by the highest values in the lower troposphere, but NOSCAV, being similar or lower than COM close to the surface, yields significantly higher $\mathrm{H}_{2} \mathrm{O}_{2}$ values than the other simulations above $2 \mathrm{~km}$ altitude. As expected, the NOSCAV simulation does not reproduce the measured $\mathrm{H}_{2} \mathrm{O}_{2}$ mixing ratios, and strongly overestimates the mixing ratios at altitudes above $2 \mathrm{~km}$. Similarly, in the EASY simulation the missing sinks by aqueous phase chemistry result in an overestimation relative to the observations. EASY2 calculates higher values than COM and SCM, but still lower than EASY. This is mainly restricted to the lower and middle tro- posphere, whereas in the upper troposphere, in which only small amounts of liquid water are available for chemical reactions in droplets, the differences between the simulations including the wet removal are smaller because of the rapid photolytical destruction. The COM and SCM simulations both lead to too high mixing ratios compared to the TOPSE data, although they are in reasonable agreement with the TRACE-P data, with the mean value well within the range of the measurements.

We conclude that for a realistic description of lower and middle tropospheric $\mathrm{H}_{2} \mathrm{O}_{2}$ mixing ratios at least the basic cloud and precipitation chemistry of this compound must be included in the model (i.e., SCM). An enhanced scavenging coefficient, i.e. larger than expected from Henry's law equilibrium, might be used as an approximation, but this cannot be determined easily for all conditions in the troposphere. Additionally, such an approximation suppresses important chemical feedbacks.

\subsubsection{Sulphur dioxide $\left(\mathrm{SO}_{2}\right)$}

Since $\mathrm{SO}_{2}$ is relatively short-lived, the distribution near the surface, presented in Fig. 12, shows strong gradients with the highest values close to the emission centres, i.e. Europe, eastern China, and additionally the eastern USA, India, SaudiArabia and Chile. Over the ocean the DMS (dimethylsulphide) oxidation and to a lesser extent ship emissions result in average mixing ratios of less than $0.5 \mathrm{nmol} / \mathrm{mol}$. In case of a reduced aqueous phase chemistry as in the SCM simulation, in which the main oxidation of S(IV) to S(VI) by $\mathrm{H}_{2} \mathrm{O}_{2}$ and $\mathrm{O}_{3}$ is nevertheless considered, the differences to the reference are relatively small except in the heavily polluted regions near the strongest $\mathrm{SO}_{2}$ sources. This results mainly from the altered $\mathrm{H}_{2} \mathrm{O}_{2}$ mixing ratios, and the consequent changes in oxidant mixing ratios (indirect effect), but also from the more detailed sulphur chemistry in the aqueous phase, e.g., interactions between oxidised sulphur and nitrogen compounds (direct effect). Overall, in SCM this leads to slightly enhanced $\mathrm{SO}_{2}$ mixing ratios compared to $\mathrm{COM}$, both close to the surface and at higher altitudes.

In the EASY simulation the aqueous phase oxidation of sulphur dioxide is neglected, i.e., a main chemical sink is missing, and the scavenging is less efficient as in SCM or COM. This leads to globally higher mixing ratios, most strongly in the regions near the emission sources. In EASY2 the dissociation of $\mathrm{SO}_{2}$ in the liquid is taken into account, but the liquid phase oxidation is still not considered. This cannot be easily parameterised with the help of a coefficient since it depends not only on the $\mathrm{pH}$, but also on the dissolved oxidant concentrations, which show large variability in time and space (e.g., $\mathrm{H}_{2} \mathrm{O}_{2}$, cf. Fig. 10). Consequently, the atmospheric content of sulphur dioxide is still overestimated and the sulphate wet deposition is underestimated (cf. Table 4).

In the NOSCAV simulation higher mixing ratios at the surface are calculated, too, but in this case they are not as high as 
(a) $\mathrm{SO}_{2}$ surface layer

mixing ratio (nmol/mol) $(\mathrm{COM})$

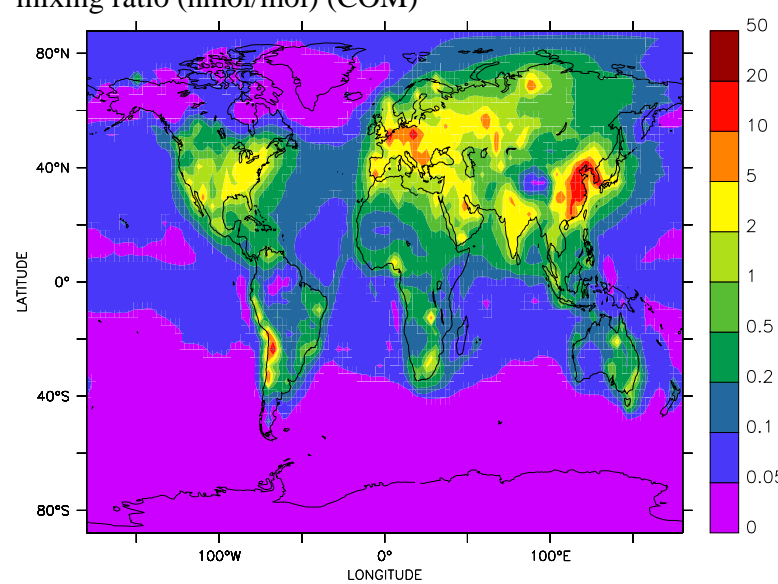

(c) absolute difference

(nmol/mol) (EASY-COM)

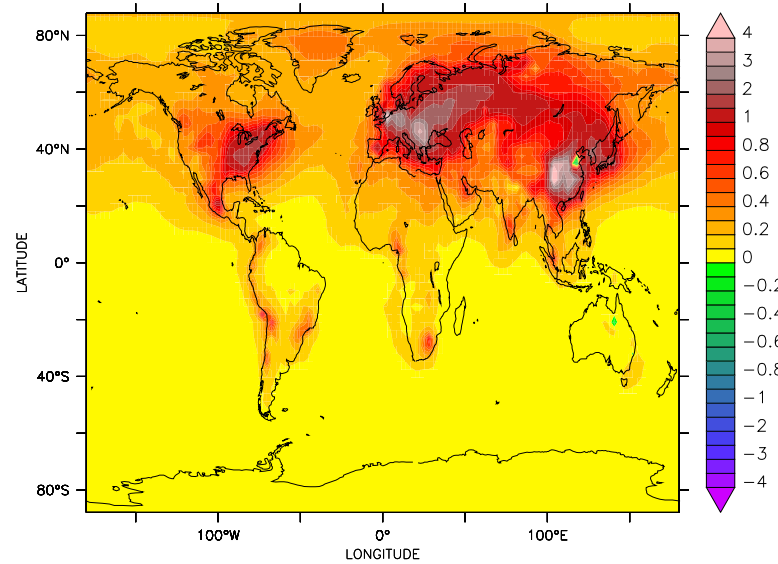

(b) absolute difference

(nmol/mol) (SCM-COM)

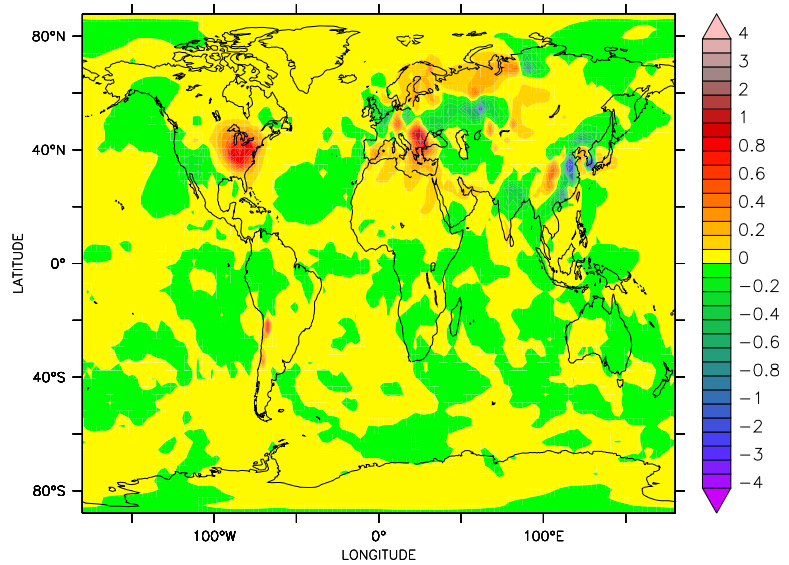

(d) absolute difference

(nmol/mol) (EASY2-COM)

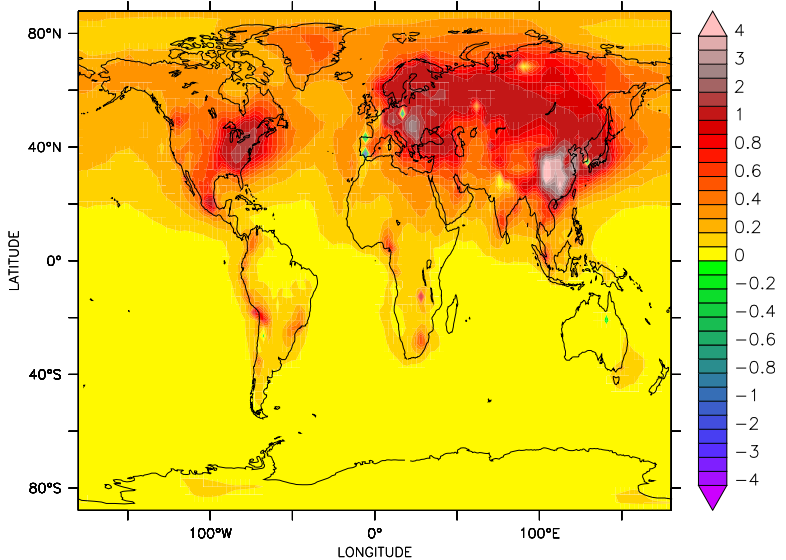

Fig. 12. Comparison of the annual average $\mathrm{SO}_{2}$ surface layer mixing ratio for the four sensitivity simulations, displayed similarly as in Fig. 6.
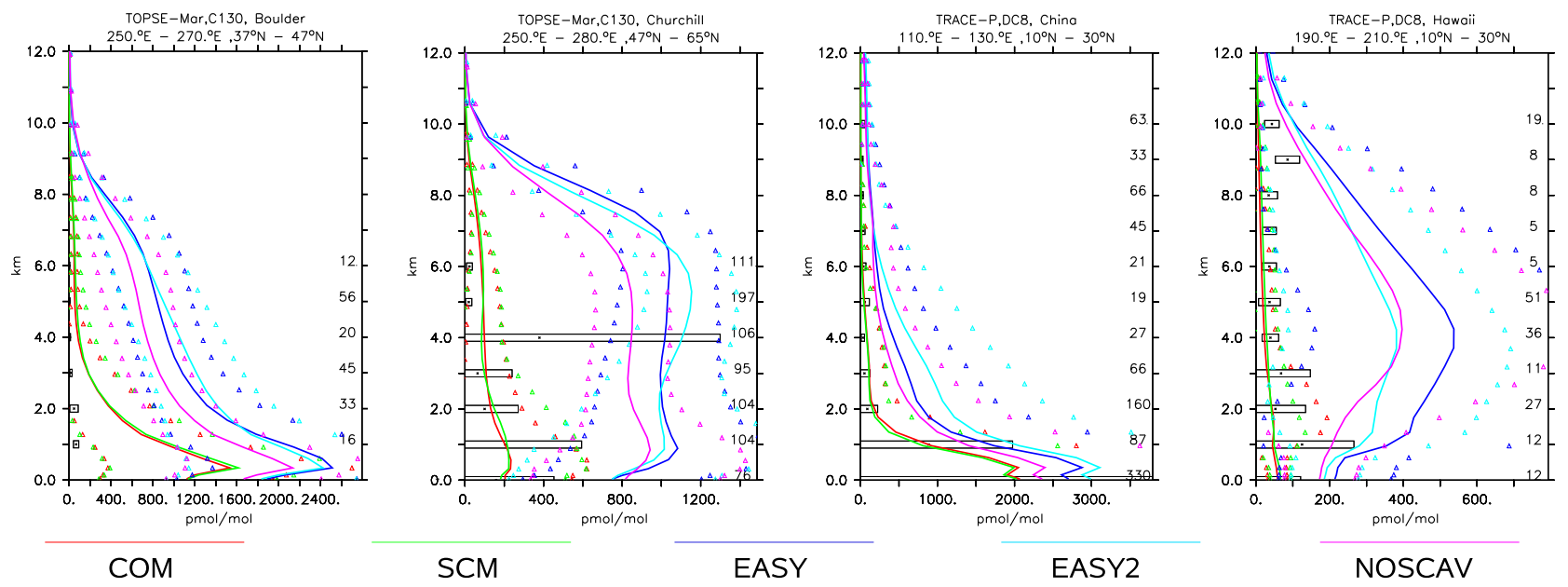

Fig. 13. As Fig. 7, but for $\mathrm{SO}_{2}$. 
in EASY, mainly related to the more efficient vertical transport. The overall global mass of $\mathrm{SO}_{2}$ is not highest in this simulation, since the increased oxidising capacity leads to an amplified $\mathrm{H}_{2} \mathrm{SO}_{4}$ production in the gas phase, resulting in higher $\mathrm{S}(\mathrm{VI})$ and lower $\mathrm{S}(\mathrm{IV})$ content of the atmosphere. In the EASY, EASY2 and NOSCAV simulations the absolute amounts of $\mathrm{SO}_{2}$ are by a factor of up to 3 larger than in the $\mathrm{COM}$ and SCM simulations.

The comparison with the Emmons et al. (2000) data in Fig. 13 for the TOPSE campaign shows a strong overestimation for all simulations close to the surface over Boulder, whereas for Churchill, the COM and SCM simulations largely capture the observed $\mathrm{SO}_{2}$. This is also valid for the TRACE-P data over China and Hawaii. Only in the lower two kilometres the mixing ratios at some specific locations are overestimated. However, since this occurs in all sensitivity studies it might indicate that emissions are overestimated and/or that mixing between the boundary layer and free troposphere is underestimated. Nevertheless, at typical cloud base levels between one and two kilometres altitude, both the COM and SCM simulation capture the efficient uptake into clouds and precipitation and subsequent wet deposition of sulphur compounds, indicating that scavenging processes are well represented. The weaknesses of EASY, EASY2 and NOSCAV are obvious, because the simulated gas phase mixing ratios are substantially overestimated compared to the observed profiles. The dissociation of $\mathrm{SO}_{2}$ in the droplets taken into account in EASY2 does not contribute efficiently to a better representation of the S(VI) uptake and wet removal.

In summary, the scavenging and wet deposition description by the effective or physical Henry's law coefficients is not sufficient to simulate mixing ratios as low as observed, whereas a basic aqueous phase chemistry (such as SCM) oxidising dissolved $\mathrm{SO}_{2}$ yields more realistic values.

\subsubsection{Formaldehyde (HCHO)}

Formaldehyde (HCHO) is moderately soluble and takes part in only few reactions in the liquid phase (e.g. A4105: $\mathrm{HCHO}+\mathrm{OH} \rightarrow \mathrm{HCOOH}+\mathrm{HO}_{2}$ ). Nevertheless, the liquid phase (wet deposition and aqueous phase chemistry) is one of the sinks to consider in global budgets, even though gasphase chemical processes are globally dominant and dry deposition is also important, based on the analysis of the source and sink processes involving $\mathrm{HCHO}$ in the model simulations of this study.

The near-surface mixing ratios are presented for the COM simulation in the upper left panel of Fig. 14. Highest mixing ratios typically occur over the tropical rain forests as a result of biogenic NMHC emissions and subsequent oxidation reactions, whereas in some regions anthropogenic NMHC are also significant. The differences of SCM to the COM simulation mainly result from the indirect effect (since only few additional reactions in the aqueous phase are considered in COM (e.g., A4105, A4109, A4110b of the aqueous phase chemistry reactions, see supplement)). They are most pronounced in regions where mixing ratios are highest. For instance, significant differences occur in polluted industrial regions, in which the oxidation capacity of the troposphere is modified in the SCM simulation setup compared to COM. This also applies to the rainforest regions, where hydrocarbon compounds compete for the available oxidants.

The differences between EASY and COM are similar, again mainly due to the indirect effects. This is evident since there are no aqueous phase chemical reactions including HCHO in SCM and EASY. Therefore, only the altered oxidant distributions can contribute to the patterns of relative differences between simulations, as well as the neglect of the gas phase diffusion limitation. This is also valid for EASY2 (lower right panel of Fig. 14), in which HCHO is treated as in EASY. Consequently, the small differences in the average near surface distributions between EASY and EASY2 are related to the indirect effects of the modified oxidation capacity.

By neglecting scavenging (NOSCAV) the formaldehyde mixing ratios near the surface over the continents are generally lower than in the COM simulation. Similar as for $\mathrm{H}_{2} \mathrm{O}_{2}$, the vertical redistribution of HCHO by convection, without the balancing downward transport in precipitation and the convective transport of oxidants, are the main causes for these patterns. For the same reason in the middle and upper troposphere the overall mixing ratios are globally higher in NOSCAV than in COM.

The representation of the mixing ratio profiles as measured during the TOPSE and TRACE-P campaigns is realistic for all simulations, with COM and SCM usually closest to the observations, and small differences between all simulations. The vertical shape is also captured relatively well by all sensitivity studies. Since wet deposition is only of minor importance for the formaldehyde budget, the differences in the vertical HCHO distributions are largely determined by differences in the gas phase chemistry (indirect effects).

\subsubsection{Summary and discussion}

Since there is interaction between the various species, some of the indirect effects can only be explained sequentially. Due to less scavenging of $\mathrm{HNO}_{3}$ (and also HONO and $\mathrm{HNO}_{4}$, which is taken into account only for COM) higher mixing ratios of $\mathrm{NO}_{\mathrm{x}}$ are found in the polluted regions of the SCM simulation. This higher nitrogen oxide content leads to an enhanced $\mathrm{O}_{3}$ production rate, and consequently to higher ozone mixing ratios in SCM compared to COM. The higher ozone enhances the $\mathrm{OH}$ and $\mathrm{H}_{2} \mathrm{O}_{2}$ mixing ratios. This in turn can lead to enhanced formaldehyde formation from the degradation of higher NMHCs and to a more efficient oxidation of $\mathrm{SO}_{2}$ in the aqueous phase.

A statistical analysis of the sensitivity simulations for several species, comparing our model results to observations of the updated Emmons et al. (2000) dataset, is shown by the 
(a) $\mathrm{HCHO}$ surface layer mixing ratio (nmol/mol) $(\mathrm{COM})$ mixing ratio $(\mathrm{nmol} / \mathrm{mol})(\mathrm{COM})$

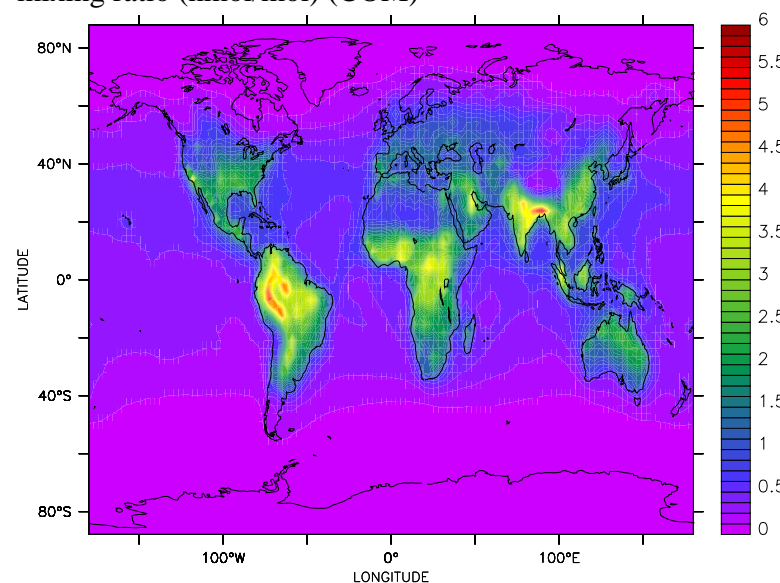

(c) absolute difference

(nmol/mol) (EASY-COM)

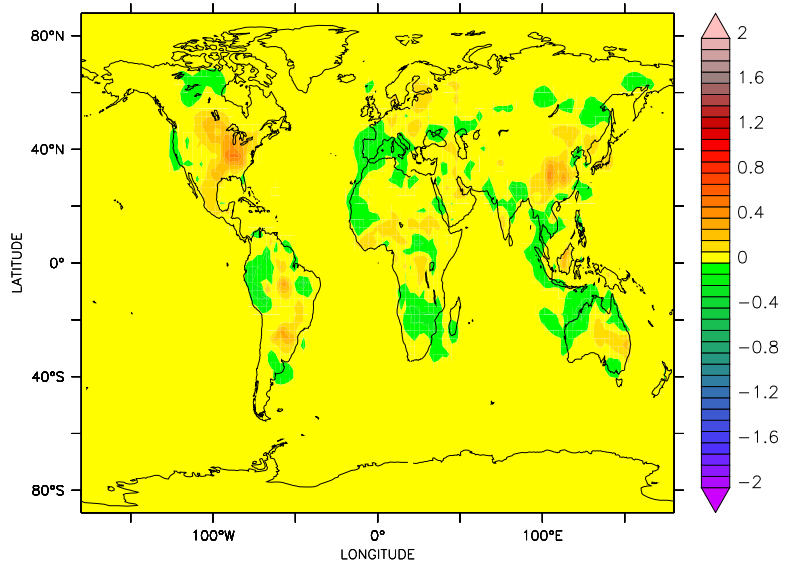

(b) absolute difference

(nmol/mol) (SCM-COM)

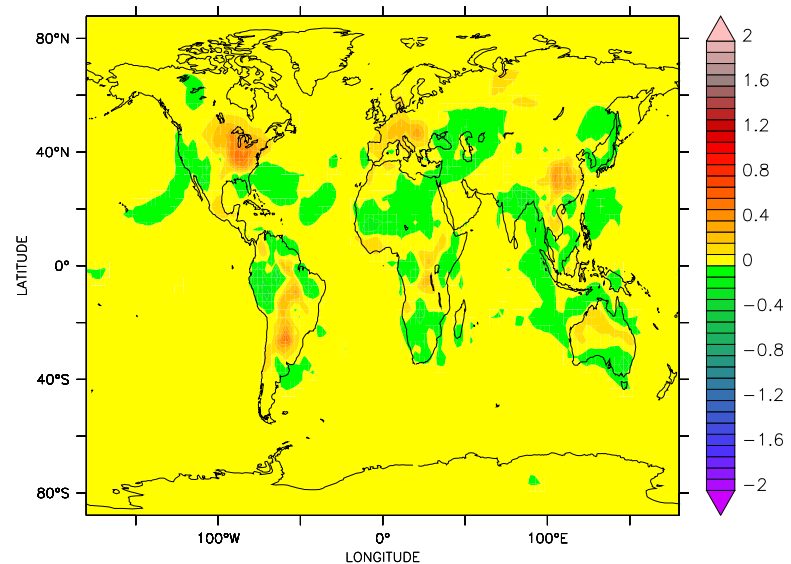

(d) absolute difference

(nmol/mol) (EASY2-COM)

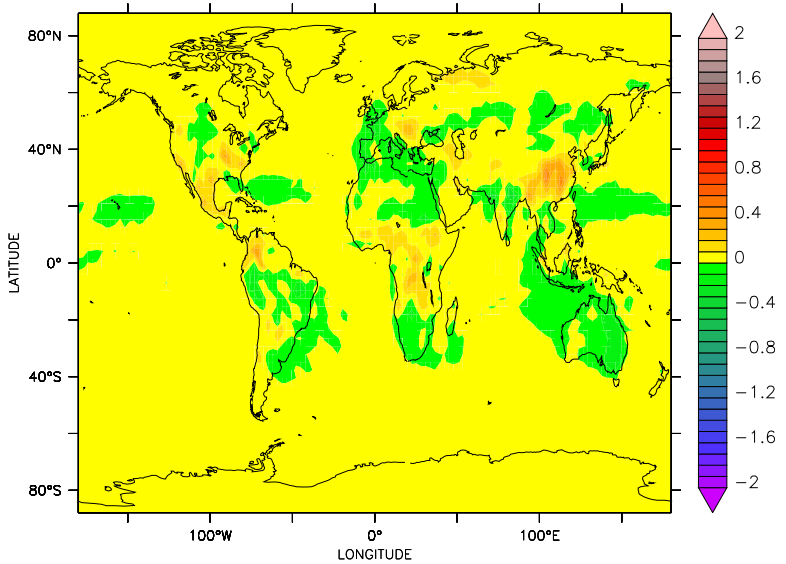

Fig. 14. Comparison of the annual average HCHO surface layer mixing ratio for the four sensitivity simulations, displayed similarly as in Fig. 6.
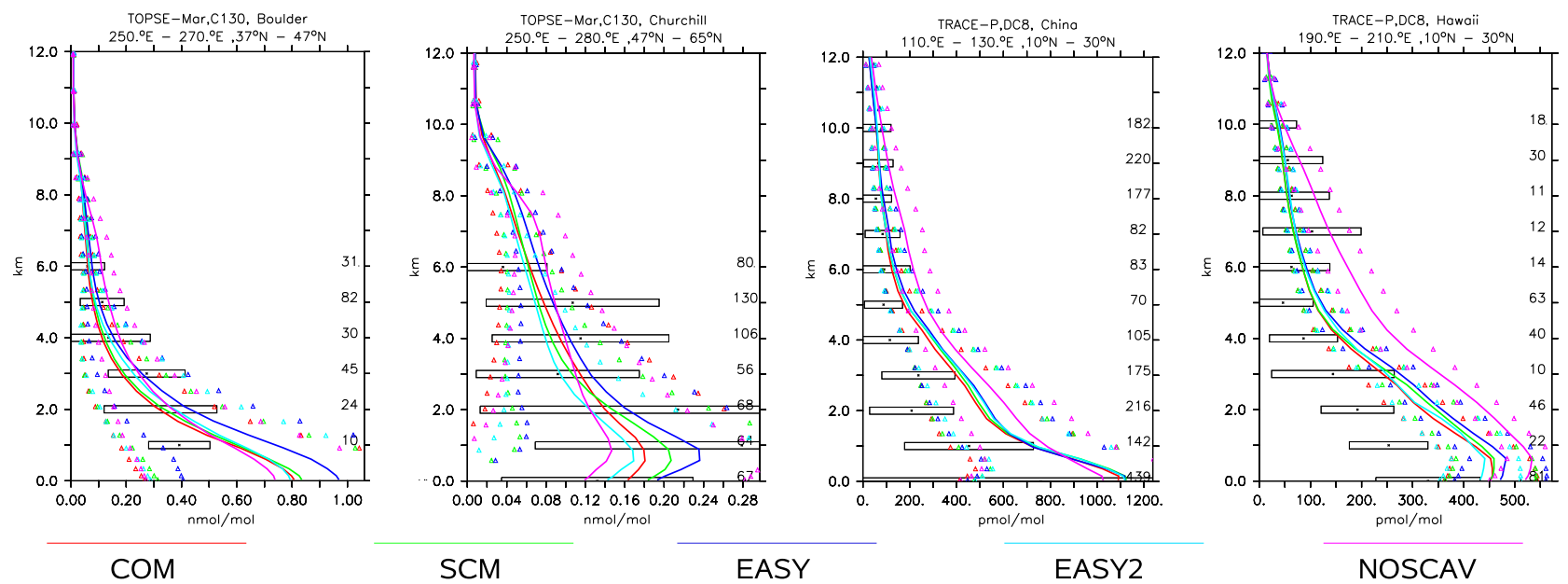

Fig. 15. As Fig. 7, but for HCHO. 


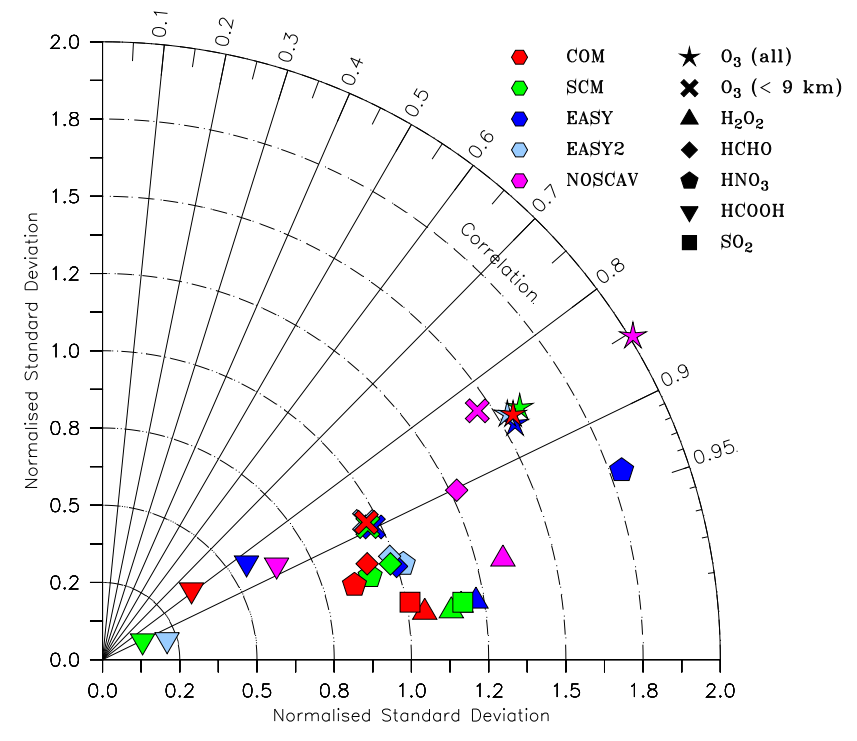

Fig. 16. Taylor diagram depicting the correlation and the normalised standard deviation $\sigma^{\star}$ of the simulations with the Emmons et al. (2000) database of observations. The different simulations are represented with different colours, the selected species with different symbols.

Taylor diagram in Fig. 16. In addition, Table 5 lists the mean biases in units of standard deviations.

With respect to ozone it appears that the overall performance of the COM and SCM simulations, with a correlation of $R \approx 0.85$ and a normalised $\sigma^{\star}>1.5$, is not as good as in Jöckel et al. (2006), and we emphasise that these results are strongly influenced by $\mathrm{O}_{3}$ in the upper troposphere through transport from the stratosphere. Not considering the results above $9 \mathrm{~km}$ altitude, we achieve a better correlation $(R \approx 0.9)$ and an almost ideal $\sigma^{\star}$ close to one. The quality of the EASY and EASY2 simulations with respect to spatial variation and correlation are comparably good, whereas the NOSCAV simulation is substantially worse.

If we additionally take into account the bias for $\mathrm{O}_{3}$ (Table 5), the COM simulation performs best, although SCM is almost of comparable quality. The EASY setup appears less suited to adequately simulate ozone, whereas with the help of the EASY2 setup comparable agreement with the simulations explicitely calculating cloud and precipitation chemistry is achieved.

Also for $\mathrm{H}_{2} \mathrm{O}_{2}$ the COM simulation achieves the best agreement with observations, with a very high correlation, $R>0.98$, and a $\sigma^{\star}$ close to unity. SCM is not very different with respect to $R$; however, the temporal and spatial variation is less well captured. Again EASY seems to perform reasonably well with respect to the correlation and $\sigma^{\star}$, although the $\mathrm{COM}$ results are clearly superior. A bias in COM is nearly absent, small in SCM, enhanced in EASY2, and much larger in the EASY setup.
Table 5. Bias in units of standard deviation (geometric average of model and observations) for the individual species in the five simulations.

\begin{tabular}{lccccc}
\hline Species & COM & SCM & EASY & EASY2 & NOSCAV \\
\hline $\mathrm{O}_{3}$ & 0.25 & 0.30 & 0.38 & 0.28 & 2.03 \\
$\mathrm{O}_{3}$ below $9 \mathrm{~km}$ & 0.10 & 0.15 & 0.25 & 0.13 & 2.03 \\
$\mathrm{H}_{2} \mathrm{O}_{2}$ & -0.01 & 0.03 & 0.16 & 0.12 & 0.76 \\
$\mathrm{HCHO}$ & 0.13 & 0.21 & 0.29 & 0.23 & 0.87 \\
$\mathrm{HNO}_{3}$ & -0.22 & -0.22 & 0.41 & -0.06 & 4.32 \\
$\mathrm{HCOOH}_{\mathrm{SO}_{2}}$ & -0.37 & -4.59 & -0.04 & -4.52 & -0.53 \\
& -1.18 & -1.01 & 1.81 & 1.69 & 1.22 \\
\hline
\end{tabular}

The performance of the COM model setup for $\mathrm{SO}_{2}$ is similarly good, again slightly better than SCM. In contrast, in the EASY and EASY2 setup the $\mathrm{SO}_{2}$ observations are poorly reproduced (out of scale in Fig. $16, \sigma^{\star} \approx 6$ ), caused by the neglect of in-cloud oxidation of $\mathrm{SO}_{2}$ in these setups. On the other hand, a significant bias is found for both COM and $\mathrm{SCM}$, both underestimating $\mathrm{SO}_{2}$ mixing ratios, whereas the bias in EASY is similar but of opposite sign. The underestimation in COM and SCM is partly a consequence of neglecting volcanic $\mathrm{SO}_{2}$ emissions (globally $\approx 8-10 \mathrm{Tg} \mathrm{S} / \mathrm{yr}$ according to Graf et al. (1997)), of the process description of convective scavenging and wet deposition, and to a lesser extent due to the uncertainty in the parameterised marine sulphur (DMS) emissions. In some polluted regions the model $\mathrm{SO}_{2}$ emissions might be overestimated (e.g., too high surface mixing ratios in China in the third panel of Fig. 13), although the wet deposition of sulphate seems to agree well with observations.

Nitric acid is also represented quite well by the model, with SCM being slightly better with respect to the variability compared to COM, but with a similar correlation. Also EASY is similarly good with respect to these two parameters, because $\mathrm{HNO}_{3}$ scavenging is largely controlled through its high solubility. However, from the bias it appears that both COM and SCM underestimate the gas phase $\mathrm{HNO}_{3}$ mixing ratios, but less than for $\mathrm{SO}_{2}$, whereas in $\mathrm{EASY} \mathrm{HNO}_{3}$ is overestimated more strongly. EASY2 seems to agree very well with the observations, however as mentioned above, the deposition sinks are much stronger than in the observations and other simulations.

The model appears to be very well suited for simulating formaldehyde mixing ratios; comparably good values with a high correlation $R>0.95$ for COM and SCM and $\sigma^{\star}$ varying between $\approx 0.9$ and 1 are achieved. In all simulations HCHO seems slightly overestimated, though least in COM.

Formic acid $(\mathrm{HCOOH})$, not discussed in detail above, is not captured very well. Even though the correlation exceeds 0.8 , the variability is not captured accurately, being best in NOSCAV and EASY, indicating that the source description of $\mathrm{HCOOH}$ is inadequate. The biases are all negative, pointing to an underestimation of gas phase mixing ratios. Again, 
the bias is smallest for COM, although improvements of the processes that control $\mathrm{HCOOH}$ in the model are required.

In summary, the COM simulation results agree best with the observations, show the lowest biases, the highest correlations, and normalised $\sigma^{\star}$ values closest to one. This implies that our detailed treatment of cloud and precipitation chemistry improves the simulated trace gas mixing ratios and distributions, and most realistically represents the chemical composition of the troposphere. The effective Henry's law coefficients (as in EASY2) usually applied for wet deposition calculations in global chemistry models can achieve realistic mixing ratios for some species (e.g., $\mathrm{HNO}_{3}$ or $\mathrm{O}_{3}$ ), whereas for other compounds this approach is insufficient (e.g., $\mathrm{SO}_{2}$ ).

Due to the multitude of direct and indirect effects of multiphase chemical processes, the overall influence of clouds and precipitation cannot easily be quantified. However, we reiterate that in contrast to most previous studies in our simulations additionally to cloud chemical effects the chemical processes in falling precipitation are taken into account.

For example, Liang and Jacob (1997) rate the influence of multiphase chemistry on ozone as minor, whereas Lelieveld and Crutzen (1991) rate it to be important. It is critical to carefully distinguish which processes have actually been addressed in these studies. If cloud and precipitation processes are not considered (as in NOSCAV), the effects on many trace gases (even the poorly soluble $\mathrm{O}_{3}$ ) are very large, as indicated by Lelieveld and Crutzen (1991), who compared the overall effects between simulations with and without clouds. Even by considering highly simplified aqueous phase sink processes (in EASY) the effects of clouds on ozone are significant. Liang and Jacob (1997), on the other hand, consider a different scenario on a regional scale, more comparable to the differences between the SCM and COM simulations (SCM including a realistic description of scavenging and deposition, and COM additionally considering comprehensive liquid phase chemistry). As analysed with the help of Figs. 8 and 9 (also confirmed by additional figures in the supplement) this influence on global tropospheric $\mathrm{O}_{3}$ is small, especially also because localised positive and negative effects tend to cancel through transport processes (Barth et al., 2002). Due to the low solubility of $\mathrm{O}_{3}$, the direct effect of relatively detailed cloud chemistry is small. For compounds with a larger solubility this direct effect gains importance as well as the indirect effects. Furthermore, transition metal chemistry in clouds, neglected in the present work, may additionally lead to ozone loss, as suggested by Matthijsen et al. (1997), although in their regional model the direct effect on $\mathrm{O}_{3}$ is small. Zhang et al. (2006) derive a strong dependence of aqueous phase chemistry on ambient $\mathrm{NH}_{3}, \mathrm{H}_{2} \mathrm{O}_{2}$ and $\mathrm{SO}_{2}$ mixing ratios, studied on the cloud scale. This is confirmed in our study for the global scale. Overall, most studies consistently find that cloud and precipitation processes have a significant influence on tropospheric chemistry on all scales.

Atmos. Chem. Phys., 7, 2733-2757, 2007

\section{Conclusions}

Our model results, considering aqueous phase chemistry in clouds and precipitation, show that the representation of scavenging according to physical Henry's law coefficient alone is not sufficiently accurate for tropospheric chemistry simulations. Furthermore, the applicability of effective Henry's law coefficients is limited because equilibrium constants are highly dependent on the chemical composition of the aqueous phase, which can vary strongly. By considering a basic (minimum) chemical reaction mechanism for cloud and precipitation droplets the accuracy of the simulation results improve substantially. Nevertheless, the use of the ECHAM5/MESSy1 model as in the COM setup, including comprehensive multiphase chemistry, yields superior agreement with observed wet deposition fluxes, especially in view of the uncertainties associated with the heterogeneity of precipitation and wet deposition patterns.

For the first time the prognostic treatment of ionconcentrations in the droplets (including $\mathrm{H}_{3} \mathrm{O}^{+}$) with the newly developed SCAV submodel (Tost et al., 2006a) enables the explicit computation of $\mathrm{pH}$ values of clouds and precipitation on a global scale. The simulated global $\mathrm{pH}$ distributions agree well with observations. Since observations are scarce and mostly limited to elevated measurement stations (thus sampling orographic clouds) the results indicate that some detailed regional features are not resolved in sufficient detail. Improved model simulations may be expected from a higher model resolution and improvements of the aqueous phase chemistry and scavenging model formulations. For instance, the interaction of trace species with ice clouds and falling frozen precipitation will be taken into account in detail as a next step.

The simulations of detailed cloud and precipitation chemistry point to direct and indirect influences on the global distributions of many trace gases. The overall effects range from relatively small, e.g., for global $\mathrm{O}_{3}(<10 \%)$, to very large for $\mathrm{HNO}_{3}, \mathrm{SO}_{2}, \mathrm{H}_{2} \mathrm{O}_{2}$ and intermediate for $\mathrm{HCHO}$. The detailed treatment of aqueous phase chemistry generally improves the accuracy of model simulated tropospheric trace gas concentrations, including $\mathrm{O}_{3}$. Yet, a simplified and computationally much cheaper mechanism (SCM) performs sufficiently well, and may be used in long-term simulations.

Acknowledgements. We acknowledge the work of G.-J. Roelofs, who introduced the first scavenging mechanism in ECHAM4, as well as L. Ganzeveld for the implementation into ECHAM5, providing a starting point for the present study. Additionally, we thank A. Bott for the co-supervision of the PhD thesis of $\mathrm{H}$. Tost on which this paper is based. We thank F. Dentener for providing the collection of deposition data and acknowledge the work of all the measurement initiatives for the observational data. Furthermore, we wish to acknowledge the use of the Ferret program for analysis and graphics in this paper. Ferret is a product of NOAA's Pacific Marine Environmental Laboratory. (Information is available at http://ferret.pmel.noaa.gov/Ferret/). Additionally we thank all 
MESSy developers and users for their support, hints, proposals and discussions. This study is part of the ENIGMA project; the authors thank the Max Planck Society for support and funding.

Edited by: M. Dameris

\section{References}

Aikawa, M., Hiraki, T., Shoga, M., and Tamaki, M.: Fog and precipitation chemistry at Mt. Rokko in Kobe, April 1997-March 1998, Water Air Soil Pollut., 130, 1517-1522, 2001.

Asman, W. A. H.: Parameterization of below-cloud scavenging of highly soluble gases under convective conditions, Atmos. Environ., 29, 1359-1368, 1995.

Atlas, E. L., Ridley, B. A., and Cantrell, C. A.: The Tropospheric Ozone Production about the Spring Equinox (TOPSE) Experiment: Introduction, J. Geophys. Res., 108, 8353, doi: 10.1029/2002JD003172, 2003.

Barth, M. C., Hess, P. G., and Madronich, S.: Effect of marine boundary layer clouds on tropospheric chemistry as analyzed in a regional chemistry transport model, J. Geophys. Res., 107, 4126, doi:10.1029/2001JD000468, 2002.

Barth, M. C., Sillman, S., Hudman, R., Jacobson, M. Z., Kim, C.H., Monod, A., and Liang, J.: Summary of the cloud chemistry modeling intercomparison: Photochemical box model simulation, J. Geophys. Res., 108, 4214, doi:10.1029/2002JD002673, 2003.

Berglen, T. F., Berntsen, T. K., Isaksen, I. S. A., and Sundet, J. K.: A global model of the coupled sulpfur/oxidant chemistry in the tropsphere: The sulfur cycle, J. Geophys. Res., 109, D19310, doi:10.1029/2003JD003948, 2004.

Best, A. C.: The size distribution of raindrops, Q. J. Roy. Meteor. Soc., 76, 16-36, 1950.

Bott, A. and Carmichael, G. R.: Multiphase chemistry in a microphysical radiation fog model - a numerical study, Atmos. Environ., 27, 503-522, 1993.

Chameides, W. L. and Davis, D. D.: The free radical chemistry of cloud droplets and its Impact upon the composition of rain, J. Geophys. Res., 87, 4863-4877, 1982.

Crutzen, P. J. and Lawrence, M. G.: The Impact of Precipitation Scavenging on the Transport of Trace Gases: A 3-Dimensional Model Sensitivity Study, J. Atmos. Chem., 37, 81-112, 2000.

Damian, V., Sandu, A., Damian, M., Potra, F., and Carmichael, G. R.: The kinetic preprocessor KPP - a software environment for solving chemical kinetics, Comput. Chem. Eng., 26, 15671579, 2002.

Dentener, F., Drevet, J., Lamarque, J. F., Bey, I., Eickhout, B., Fiore, A. M., Hauglustaine, D., Horrowitz, L. W., Krol, M., Kulshrestha, U. C., Lawrence, M., Galy-Lacaux, C., Rast, S., Shindell, D., Stevenson, D., van Noije, T., Atherton, C., Bell, N., Bergman, D., Butler, T., Cofala, J., Collins, B., Doherty, R., Ellingsen, K., Galloway, J., Gauss, M., Montanaro, V., Müller, J. F., Pitari, G., Rodriguez, J., Sanderson, M., Solmon, F., Strahan, S., Schultz, M., Sudo, K., Szopa, S., and Wild, O.: Nitrogen and sulfur deposition on regional and global scales: a multimodel evaluation, Global Biogeochem. Cycles, 20, GB4003, doi: 10.1029/2005GB002672, 2006.

Dentener, F. J.: Heterogeneous Chemistry in the Troposphere, Ph.D. thesis, Universiteit Utrecht, 1993.
Dentener, F. J. and Crutzen, P. J.: Reaction of $\mathrm{N}_{2} \mathrm{O}_{5}$ on Tropospheric Aerosols: Impact on the Global Distributions of $\mathrm{NO}_{\mathrm{x}}$, $\mathrm{O}_{3}$ and $\mathrm{OH}$, J. Geophys. Res., 98, 7149-7163, 1993.

Dentener, F. J. and Crutzen, P. J.: A three-dimensional model of the global ammonia cycle, J. Atmos. Chem., 19, 331-369, 1994.

Emmons, L. K., Hauglustaine, D. A., Müller, J.-F., carroll, M. A., Brasseur, G. P., Brunner, D., Staehelin, J., Thouret, V., and Marenco, A.: Data composites of airborne observations of tropospheric ozone and its precursors, J. Geophys. Res., 105, $20497-$ 20538, 2000.

Ervens, B., George, C., Williams, J. E., Boxton, G. V., Salmon, G. A., Bydder, M., Wilkinsons, F., Dentener, F., Mirabel, P., Wolke, R., and Herrmann, H.: CAPRAM 2.4 (MODAC mechanism): An extended and condensed tropospheric aqueous phase mechanism and its application, J. Geophys. Res., 108, 4426, doi: 10.1029/2002JD002202, 2003.

Fahey, K. M. and Pandis, S. N.: Optimizing model performance: variable size resolution in cloud chemistry modeling, Atmos. Environ., 35, 4471-4478, 2001.

Fahey, K. M. and Pandis, S. N.: Size-resolved aqueousphase atmospheric chemistry in a three-dimensional chemical transport model, J. Geophys. Res., 108, 4690, doi:10.1029/ 2003JD003564, 2003.

Feichter, J., Kjellström, E., Rohde, H., Dentener, F., Lelieveld, J., and Roelofs, G.-J.: Simulation of the tropospheric sulfur cycle in a global climate model, Atmos. Environ., 30, 1693-1707, 1996.

Filoso, S., Williams, M. R., and Melack, J. M.: Composition and deposition of throughfall in a flooded forest archipelago (Negro River, Brazil), Biogeochemistry, 45, 169-195, 1999.

Galy-Lacaux, C. and Modi, A. I.: Precipitation chemistry in the Sahelian Savanna of Niger, Africa, J. Atmos. Chem., 30, 319343, 1998.

Ganzeveld, L., Lelieveld, J., and Roelofs, G.-J.: A dry deposition parameterization for sulfur oxides in a chemistry and general circulation model, J. Geophys. Res., 103, 5679-5694, 1998.

Graf, H.-F., Feichter, J., and Langmann, B.: Volcanic sulfur emissions: Estimates of source strength and its contribution to the global sulfate distribution, J. Geophys. Res., 102, 10 727-10 738, 1997.

Hagemann, S., Arpe, K., and Roeckner, E.: Evaluation of the hydrological cycle in the ECHAM5 model, J. Climate, 19, 3810-3827, 2006.

Hicks, B. B.: A climatology of wet deposition scavenging ratios for the United States, Atmos. Environ., 39, 1585-1596, 2005.

Jacob, D. J.: Chemistry of $\mathrm{OH}$ in remote clouds and its role in the production of formic acid and peroxymonosulfate, J. Geophys. Res., 91, 9807-9826, 1986.

Jacob, D. J., Logan, J. A., Yevich, R. M., Gardner, G. M., Spivakovsky, C. M., Wofsy, S. C., Munger, J. W., Sillman, S., Prather, M. J., Rodgers, M. O., Westberg, H., and Zimmerman, P. R.: Simulation of Summertime Ozone over North America, J. Geophys. Res., 98, 14 797-14 816, 1993.

Jacob, D. J., Crawford, J. H., Kleb, M. M., Connors, V. S., Bendura, R. J., Raper, J. L., Sachse, G. W., Gille, J. C., Emmons, L., and Heald, C. L.: Transport and Chemical Evolution over the Pacific (TRACE-P) aircraft mission: Design, execution and first results, J. Geophys. Res., 108, 9000, doi:10.1029/2002JD003276, 2003.

Jacobson, M. Z.: Fundamentals of Atmopsheric Modeling, Cambridge University Press, 2005. 
Jeuken, A. B. M., Siegmund, P. C., Heijboer, L. C., Feichter, J., and Bengtsson, L.: On the potential of assimilating meteorological analyses in a global climate model for the purpose of model validation, J. Geophys. Res., 101, 16939-16950, 1996.

Jöckel, P., Sander, R., Kerkweg, A., Tost, H., and Lelieveld, J.: Technical Note: The Modular Earth Submodel System (MESSy) - a new approach towards Earth System Modeling, Atmos. Chem. Phys., 5, 433-444, 2005, http://www.atmos-chem-phys.net/5/433/2005/.

Jöckel, P., Tost, H., Pozzer, A., Brühl, C., Buchholz, J., Ganzeveld, L., Hoor, P., Kerkweg, A., Lawrence, M. G., Sander, R., Steil, B., Stiller, G., Tanarhte, M., Taraborrelli, D., van Aardenne, J., and Lelieveld, J.: The atmospheric chemistry general circulation model ECHAM5/MESSy1: consistent simulation of ozone from the surface to the mesosphere, Atmos. Chem. Phys., 6, 50675104, 2006,

http://www.atmos-chem-phys.net/6/5067/2006/.

Kerkweg, A.: Global Modelling of Atmospheric Halogen Chemistry in the Marine Boundary Layer, Ph.D. thesis, Rheinische Friedrich-Wilhelms-Universität Bonn, Germany, 2005.

Kerkweg, A., Buchholz, J., Ganzeveld, L., Pozzer, A., Tost, H., and Jöckel, P.: Technical Note: An implementation of the dry removal processes DRY DEPosition and SEDImentation in the Modular Earth Submodel System (MESSy), Atmos. Chem. Phys., 6, 4617-4632, 2006a.

Kerkweg, A., Sander, R., Tost, H., and Jöckel, P.: Technical Note: Implementation of prescribed (OFFLEM), calculated (ONLEM), and pseudo-emissions (TNUDGE) of chemical species in the Modular Earth Submodel System (MESSy), Atmos. Chem. Phys., 6, 3603-3609, 2006b.

Kreidenweis, S. M., Walcek, C. J., Feingold, G., Gong, W., Jacobson, M. Z., Kim, C.-H., Liu, X., Penner, J. E., Nenes, A., and Seinfeld, J. H.: Modification of aerosol mass and size distribution due to aqueous-phase SO2 oxidation in clouds: Comparisons of several models, J. Geophys. Res., 108, 4213, doi: 10.1029/2002JD002697, 2003.

Kulshrestha, U. C., Granat, L., Enghardt, M., and Rodhe, H.: Review of precipitation monitoring studies in India - a search for regional patterns, Atmos. Environ., 39, 7403-7419, 2005.

Lara, L. B. L. S., Artaxo, P., Martinelli, L. A., Victoria, R. L., Camargo, P. B., Krusche, A., Ayers, G. P., Ferraz, E. S. B., and Ballester, M. V.: Chemical composition of rainwater and anthropogenic influences in the Piracicaba River Basin, Southeast Brazil, Atmos. Environ., 35, 4937-4945, 2001.

Lelieveld, J. and Crutzen, P. J.: The Role of Clouds in Tropospheric Chemistry, J. Atmos. Chem., 12, 229-267, 1991.

Lelieveld, J., Berresheim, H., Borrmann, S., Crutzen, P. J., Dentener, F. J., Fischer, H., Feichter, J., Flatau, P. J., Heland, J., Holzinger, R., Korrmann, R., Lawrence, M. G., Levin, Z., Markowicz, K. M., Mihalopoulos, N., Minikin, A., Ramanathan, V., de Reus, M., Roelofs, G. J., Scheeren, H. A., Sciare, J., Schlager, H., Schultz, M., siegmund, P., Steil, B., Stephanou, E. G., Stier, P., Traub, M., Warneke, C., Williams, J., and Ziereis, H.: Global Air Pollution Crossroads over the Mediterranean, Science, 298, 794-799, 2002.

Leriche, M., Dequillaume, L., and Chaumerliac, N.: Modeling study of strong acids formation and partitioning in a polluted cloud during wintertime, J. Geophys. Res., 108, 4433, doi: 10.1029/2002JD002950, 2003.
Levine, S. Z. and Schwartz, S. E.: In-cloud and below-cloud scavenging of nitric acid vapor, Atmos. Environ., 16, 1725-1734, 1982.

Liang, J. and Jacob, D. J.: Effect of aqueous phase cloud chemistry on tropospheric ozone, J. Geophys. Res., 102, 5993-6001, 1997.

Lin, S.-J. and Rood, R.: Multidimensional Flux-Form SemiLagrangian Transport Schemes, Mon. Wea. Rev., 124, 20462070, 1996.

Marinoni, A., Laj, P., Sellegri, K., and Mailhot, G.: Cloud chemistry at the Puy de Dôme: variability and relationships with environmental factors, Atmos. Chem. Phys., 4, 715-728, 2004, http://www.atmos-chem-phys.net/4/715/2004/.

Mason, J. B.: The Physics of Clouds, Oxford University Press, 1971.

Matthijsen, J., Builtjes, P. J. H., Meijer, E. W., and Boersen, G.: Modelling cloud effects on ozone on a regional scale: a case study, Atmos. Environ., 31, 3227-3238, 1997.

Mizak, C. A., Campbell, S. W., Luther, M. E., Carnahan, R. P., Murphy, R. J., and Poor, N. D.: Below-cloud ammonia scavenging in convective thunderstorms at a coastal research site in Tampa, FL, USA, Atmos. Environ., 39, 1575-1584, 2005.

Monod, A. and Carlier, P.: Impact of clouds on the tropospheric ozone budget: Direct effect of multiphase photochemistry of soluble organic compounds, Atmos. Environ., 33, 4431-4446, 1999.

Moore, K. F., Sherman, D. E., Reilly, J. E., and jr. Collet, J. L.: Drop size-dependent chemical composition in clouds and fogs. Part I: Observations, Atmos. Environ., 38, 1389-1402, 2004.

Mphepya, J. N., Pienaar, J. J., Galy-Lacaux, C., Held, G., and Turner, C. R.: Precipitation chemistry in semi-arid areas of Southern Africa: A case study of a rural and an industrial site, J. Atmos. Chem., 47, 1-24, 2004.

Mphepya, J. N., Galy-Lacaux, C., Lacaux, J. P., Held, G., and Pienaar, J. J.: Precipitation chemistry and wet deposition in Kruger National Park, South Africa, J. Atmos. Chem., 53, 169-183, doi: 10.1007/s10874-005-9005-7, 2006.

Pozzer, A., Jöckel, P., Tost, H., Sander, R., Ganzeveld, L., Kerkweg, A., and Lelieveld, J.: Simulating organic species with the global atmospheric chemistry general circulation model ECHAM5/MESSy1: a comparison of model results with observations, Atmos. Chem. Phys., 7, 2527-2550, 2007, http://www.atmos-chem-phys.net/7/2527/2007/.

Rasch, P. J., Feichter, J., Law, K., Mahowald, N., Penner, J., Benkovitz, C., Genthon, C., Giannakopoulos, C., Kasibhatla, P., Koch, D., Levy, H., Maki, T., Prather, M., roberts, D. L., Roelofs, G.-J., Stevenson, D., Stockwell, Z., Taguchi, S., Kritz, M., Chipperfield, M., Baldocchi, D., McMurry, P., Barrie, L., Balkanski, Y., Chatfield, R., Kjellström, E., Lawrence, M., Lee, H. N., Lelieveld, J., Noone, K. J., Seinfeld, J., Stenchikov, G., Schwartz, S., Walcek, C., and Williamson, D.: A comparison of scavenging and deposition processes in global models: results from the WCRP Cambridge Workshop of 1995, Tellus, 52B, 1025-1056, 2000.

Ravishankara, A. R.: Heterogeneous and Multiphase Chemistry in the Troposphere, Science, 276, 1058-1965, 1997.

Roeckner, E., Bäuml, G., Bonaventura, L., Brokopf, R., Esch, M., Giorgetta, M., Hagemann, S., Kirchner, I., Kornblue, L., Manzini, E., Rhodin, A., Schleese, U., Schulzweida, U., and Tompkins, A.: The atmospheric general circulation model 
ECHAM5: Part 1, Tech. Rep. 349, Max-Planck-Institut für Meteorologie, 2003.

Roeckner, E., Brokopf, R., Esch, M., Giorgetta, M., Hagemann, S., Kornblue, L., Manzini, E., Schleese, U., and Schulzweida, U.: The atmospheric general circulation model ECHAM5: Part 2, Tech. Rep. 354, Max-Planck-Institut für Meteorologie, 2004.

Roeckner, E., Brokopf, R., Esch, M., Giogetta, M., Hagemann, S., Kornblueh, L., Manzini, E., Schleese, U., and Schulzweida, U.: Sensitivity of simulated climate to horizontal and vertical resolution in the ECHAM5 atmosphere model, J. Climate, 19, 37713791, 2006.

Roelofs, G.-J. and Lelieveld, J.: Distribution and budget of $\mathrm{O}_{3}$ in the troposphere calculated with a chemistry general circulation model, J. Geophys. Res., 100, 20 983-20 998, 1995.

Rostayn, L. D. and Lohmann, U.: Simulation of the tropospheric sulfur cycle in a global model with a physically based cloud scheme, J. Geophys. Res., 107, 4592, doi:10.1029/ 2002JD002128, 2002.

Safai, P. D., Rao, P. S. P., Momin, G. A., Ali, K., Chate, D. M., and Preaveen, P. S.: Chemical composition of precipitaion during 1984-2002 at Pune, India, Atmos. Environ., 38, 1705-1714, 2004.

Sander, R.: Modeling atmospheric chemistry: Interactions between gas-phase species and liquid cloud/aerosol particles, Surv. Geophys., 20, 1-31, 1999.

Sander, R., Kerkweg, A., Jöckel, P., and Lelieveld, J.: Technical Note: The new comprehensive atmospheric chemistry module MECCA, Atmos. Chem. Phys., 5, 445-450, 2005, http://www.atmos-chem-phys.net/5/445/2005/.

Schwartz, S. E.: Mass-transport considerations pertinent to aqueous phase reactions of gases in liquid-water clouds, in: Chemistry of Multiphase Atmospheric Systems, NATO ASI Series, Vol. G6, edited by: Jaeschke, W., Springer Verlag, Berlin, pp. 415-471, 1986.

Sellegri, K., Laj, P., Marinoni, A., Dupuy, R., Legrand, M., and Preunkert, S.: Contribution of gaseous and particulate species to droplet solute composition at the Puy de Dôme, France, Atmos. Chem. Phys., 3, 1509-1522, 2003, http://www.atmos-chem-phys.net/3/1509/2003/.

Sigha-Nkamdjou, L., Galy-Lacaux, C., Pont, V., Richard, S., Sighomnou, D., and Lacaux, J. P.: Rain water chemistry and wet deposition over the equatorial forested ecosystem of Zoetele (Cameroon), J. Atmos. Chem., 46, 173-198, 2003.

Stier, P., Feichter, J., Kinne, S., Kloster, S., Vignati, E., Wilson, J., Ganzeveld, L., Tegen, I., Werner, M., Balkanski, Y., Schulz, M., and Boucher, O.: The Aerosol-Climate Model ECHAM5-HAM, Atmos. Chem. Phys., 5, 1125-1156, 2005,

http://www.atmos-chem-phys.net/5/1125/2005/.
Taylor, K. E.: Summarizing multiple aspects of model preformance in a single diagram, J. Geophys. Res., 106, 7183-7192, 2001.

Tost, H.: Global Modelling of Cloud, Convection and Precipitation Influences on Trace Gases and Aerosols, Ph.D. thesis, Rheinische Friedrich-Wilhelms-Universität Bonn, Germany, available at: http://hss.ulb.uni-bonn.de/diss_online/math_nat_fak/ 2006/tost_holger, 2006.

Tost, H., Jöckel, P., Kerkweg, A., Sander, R., and Lelieveld, J.: Technical Note: A new comprehensive SCAVenging submodel for global atmospheric chemistry modelling, Atmos. Chem. Phys., 6, 565-574, 2006a.

Tost, H., Jöckel, P., and Lelieveld, J.: Influence of different convection parameterisations in a GCM, Atmos. Chem. Phys., 6, 54755493, 2006 b.

van Aalst, M. K., van den Broek, M. M. P., Bregman, A., Brühl, C., Steil, B., Toon, G. C., Garcelon, S., Hansford, G. M., Jones, R. L., Gardiner, T. D., Roelofs, G.-J., Lelieveld, J., and Crutzen, P.: Trace gas transport in the 1999/2000 Arctic winter: comparison of nudged GCM runs with observations, Atmos. Chem. Phys., 4, 81-93, 2004,

http://www.atmos-chem-phys.net/4/81/2004/.

Vignati, E., Wilson, J., and Stier, P.: M7: An efficient sizeresolved aerosol microphysics module for large-scale aerosol transport models, J. Geophys. Res., 109, D22 202, doi:10.1029/ 2003JD004485, 2004.

von Glasow, R., Sander, R., Bott, A., and Crutzen, P. J.: Modeling halogen chemistry in the marine boundary layer. 2. Interactions with sulfur and the cloud-covered MBL, J. Geophys. Res., 107, 4323, doi:10.1029/2002JD000943, 2002.

Warneck, P.: The relative importance of various pathways for the oxidation of sulfur dioxide and nitrogen dioxide in sunlit continental fair weather clouds, Phys. Chem. Chem. Phys., 1, 54715483, 1999.

Wild, M. and Roeckner, E.: Radiative Fluxes in the ECHAM5 general circulation model, J. Climate, 19, 3792-3809, 2006.

Yin, Y., Parker, D. J. and Carslaw, K. S.: Simulation of trace gas redistribution by convective clouds - Liquid phase processes, Atmos. Chem. Phys., 1, 19-36, 2001, http://www.atmos-chem-phys.net/1/19/2001/.

Yoboué, V., Galy-Lacaux, C., Lacaux, J. P., and Sliué, S.: Rainwater chemistry and wet deposition over the wet savanna ecosystem of Lamto (Côte d'Ivoire), J. Atmos. Chem., 52, 117-141, doi: 10.1007/s10874-005-0281-z, 2005.

Zhang, L., Vet, R., and Michelangeli, D. V.: Numerical Investigation of Gas Scavenging by Weak Precipitation, J. Atmos. Chem., 54, 203-231, doi:10.1007/s10874-005-9010-x, 2006. 